\title{
An Insight into Thermodynamic Relationship Between Polymorphic Forms of Efavirenz
}

Renu Chadha, Poonam Arora, Anupam Saini, and Dharamvir Singh Jain

University Institute of Pharmaceutical Sciences, Panjab University, Chandigarh, India; Department of Chemistry, Panjab University, Chandigarh, India.

Received, December 4, 2011; Revised, January 18, 2012; Accepted, March 30, 2012; Published, April 2, 2012.

\begin{abstract}
Purpose: The aim of the work is to study the crystallization of efavirenz to understand the preferential formation of various polymorphic forms, to establish their identity, to study the transformation between the polymorphic forms on heating and to determine their free energy. Methods: Slow crystallization from different solvents under controlled conditions was employed to prepare various crystalline forms. The TGA and DSC were used to study their thermal behavior and inter-conversion of these forms. The calorimetrically determined enthalpies of solution and solubility data are utilized to determine the transition temperatures. Results: Six polymorphic forms of efavirenz are identified and characterized completely. The TGA scans of all the forms did not show any mass loss indicating absence of hydrate or solvate. The thermally induced transformations are observed in the DSC scans of five forms II-VI indicating them to be metastable which are converted to stable higher melting forms. The melting temperature and enthalpy of fusion of lower melting $\left(\right.$ Form $\left._{\mathrm{L}}\right)$ and higher melting forms $\left(\mathrm{Form}_{\mathrm{H}}\right)$ reveal that four of these polymorphic pairs are monotropically related. The enthalpies of solution of Form $\mathrm{L}$ are found to be more exothermic as compared to corresponding Form $\mathrm{H}_{\mathrm{H}}$. The transition temperature $\left(\mathrm{T}_{\mathrm{t}}\right)$ determined using enthalpy of solution and solubility data was found to be higher than the melting of both the forms except for polymorphic pair $\mathrm{VI}_{\mathrm{L}} / \mathrm{VI}_{\mathrm{H}}$. The effect of $\Delta \mathrm{C}_{\mathrm{p}}$ on transition temperature is also reported. Conclusions: The form I is found to be thermodymanically most stable but least soluble. The forms II-V are metastable and are converted irreversibly to stable forms. The enthalpy of fusion rule and virtual transition temperature provided complementary evidence for the existence of monotropy in these polymorphic pairs. However, enantiotropy is demonstrated in $\mathrm{VI}_{\mathrm{L}} / \mathrm{VL}_{\mathrm{H}}$ pair and is well established in our study. Novelty: The present study reveals the thermodynamic aspects of various isolated polymorphic forms of efavirenz. Solution calorimetry along with other techniques is used to study the transformation of one form to another. The emphasis is laid on determination of transition temperature of various polymorphic pairs which has not been reported earlier.
\end{abstract}

This article is open to POST-PUBLICATION REVIEW. Registered readers (see "For Readers") may comment by clicking on ABSTRACT on the issue's contents page.

\section{INTRODUCTION}

The tendency of pharmaceutical solids to crystallize in multiple crystal forms and the significance of this phenomenon has been well demonstrated during this decade and is a subject of fundamental, practical and legal interest (1-5). Various forms may appear during the crystallization process, depending upon the factors such as solvent, temperature, additives and preparation methods. Polymorphism can provide an opportunity to improve the physicochemical properties without changing the molecule involved $(6,7)$. The polymorphs can be modified by solvent dependent process and also by phase-phase transition that can be induced by heat or mechanical stress (8). Therefore, it is of critical importance that accurate assessment of the polymorphic behavior and correct identification of the proper polymorph of the drug substance be made in the early stages of drug development. The measurements of thermodynamic properties of the polymorphs, such as enthalpies of solution and entropy and enthalpy relationships, aid in the proper selection of the desired crystalline modification of the drug (9).

Corresponding Author: Renu Chadha: University Institute of Pharmaceutical Sciences, Panjab University, Chandigarh-160014, India.

Email: renukchadha@rediffmail.com 
Moreover, for drug substances that show polymorphism, pharmaceutical regulations require that the appropriate solid-state of bulk material be provided in which only one polymorphic form is included or specific polymorphic contents are controlled (10). It is important that crystalline form of drug substance used in solid dosage form be characterized and the appropriate form selected to ensure that the product performance with respect to manufacturability, stability, and bioavailability remains unchanged (11).

Efavirenz, (Figure 1) (4S)-6-chloro-4(cyclopropylethynyl)-4-(trifluromethyl)-1,4-

dihydro-2H-3,1-benzoxazin-2-one, is a HIV-1 specific, non-nucleoside reverse transcriptase inhibitor, used for the treatment of AIDS. Efavirenz in combination with other retroviral agents is indicated for the treatment of HIV-1 infection. Until 1999 efavirenz was not known to exist in stable crystalline form. The first patent appearing in 1999 reported the existence of five different forms (12). Soon after this report few more patents and publications appeared describing the methods for the preparation of new modifications using different solvents and anti solvents (13-18). Unfortunately, most of these patents lack in one or other aspect. The thermodynamic aspects of various polymorphs have not been taken into account and the transformation of one form to another has not been reported. There are many lacunae in the reported literature which need to be filled for complete characterization of these polymorphs.

The present work describes the preparation of different physical forms of efavirenz and their characterization using different analytical techniques. Investigations are performed on heat mediated polymorphic transformation of one form to another. Emphasis is laid on the determination of transition temperature of polymorphic pairs and to interpret whether they are monotropically or enantiotropically related. The thermodynamic stability relationship of the polymorphic pair has also been determined from their solubility and enthalpy of solution data.

\section{MATERIALS AND METHODS}

\section{Materials}

Efavirenz was obtained as a gift sample from Ranbaxy Laboratories Pvt. Ltd. (Poanta Sahib, India). Analytical grade solvents acetonitrile, hexane, methanol, pet ether n-heptane, and tetrahydrofuran (THF) (Sigma Aldrich) were used in this work. Acetate buffer $\mathrm{pH} 2.8$ was prepared by dissolving $4 \mathrm{~g}$ of anhydrous sodium acetate in water and the $\mathrm{pH}$ was adjusted to 2.8 with of glacial acetic acid and the volume was made up to $1000 \mathrm{~mL}$ (19). The Celsius scale has been used for temperature measurements.

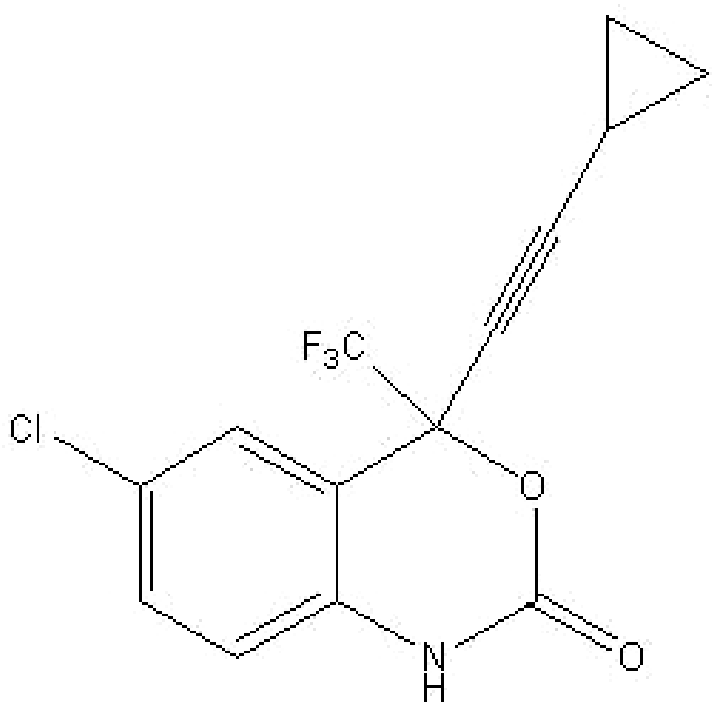

Figure 1. Chemical structure of efavirenz.

\section{Preparation of polymorphs}

The various forms of efavirenz (Form O) were obtained by recrystallization from different solvents of analytical grade. Efavirenz was recrystallized from each of the following solvents (at the following volumes and initial temperatures): acetonitrile $\left(50 \mathrm{~mL}, 75^{\circ}\right)$, hexane $\left(100 \mathrm{~mL}, 70^{\circ}\right)$, methanol $\left(100 \mathrm{~mL}, 60^{\circ}\right)$, petroleum ether $(100 \mathrm{~mL}$, $\left.50^{\circ}\right)$, n-heptane $\left(100 \mathrm{~mL}, 90^{\circ}\right)$, and tetrahydrofuran $\left(50 \mathrm{~mL}, 60^{\circ}\right)$. The saturated solutions of the drug were heated under constant stirring until most of the efavirenz dissolved and the necessary supersaturation is achieved. The solutions were then filtered and kept for crystallization at $28^{\circ}$ (slow recrystallization). The solid phase appears after few days from solution of acetonitrile (20 days); hexane and methanol (10 days); petroleum ether and nheptane ( 7 days) and tetrahydrofuran (12 days). The solutions were filtered and dried under vacuum. Taking into consideration the dynamic nature of crystallization and other kinetic factors, reproducibility of the forms was established by repeating the crystallization process under the same 
experimental conditions leading to formation of preferential polymorphs. The recrystallization from acetonitrile, hexane, methanol, petroleum ether, nheptane and tetrahydrofuran gives rise to Form I, Form II, Form III, Form IV, Form V and Form VI respectively.

\section{Thermal methods of analysis}

DSC thermograms were obtained on DSC Q20, TA Instruments-Waters LLC, USA. The calorimeter was calibrated for temperature and heat flow accuracy using the melting of pure indium $(\mathrm{mp}$ $156.6^{\circ}$ and $\Delta \mathrm{H}$ of $\left.28.45 \mathrm{Jg}^{-1}\right)$. A mass between $4-8$ $\mathrm{mg}$ was taken into the aluminium pan, covered with lid and sealed. DSC curves were obtained under a nitrogen purge of $50 \mathrm{~mL}$ per minute at a heating rate of $10^{\circ}$ per minute with the temperature range from $50-250^{\circ}$.

The TGA scans were obtained on TGA, TA Instruments-Waters LLC, USA. TGA traces were recorded at heating rates of $10^{\circ}$ per minute under a nitrogen purge of $50 \mathrm{~mL}$ per minute. Samples with masses between 5-10 $\mathrm{mg}$ were analyzed using platinum pan. Mass loss (\%) was calculated based on the mass of the original sample.

\section{X-Ray powder diffraction Analysis}

The powder diffraction patterns were recorded on an X-ray diffractometer (XPERT-PRO, PANalytical, Netherlands) with $\mathrm{Cu}$ as tube anode. The diffractograms were recorded under following conditions: voltage $40 \mathrm{kV}, 35 \mathrm{~mA}$ and fixed divergence slit using the configuration; $2 \theta$ range: $5^{\circ}$ to $40^{\circ}, 0.01$ step size, $10 \mathrm{~s}$ dwell time, Care was taken to avoid phase transformations during sample preparation. Approximately $200 \mathrm{mg}$ of samples were loaded into the sample holder. The preferred orientation effects were avoided by side loading the sample holder rather than vertically loading. Furthermore the XPERT-PRO, PANalytical X-ray diffractometer is equipped with spinning sample holders which greatly reducing the influence of preferred sample orientation.

\section{Scanning Electron Microscopy}

A Jeol JSM-6100 scanning electron microscope was used to obtain photomicrographs of efavirenz and its polymorphs. Samples were mounted on a metal stub with an adhesive tape and coated under vacuum with gold.

\section{Calorimetric study}

The enthalpy of solution and heat capacity studies of various forms were performed on Microreaction calorimeter obtained from Thermal Hazards Technology, UK.

\section{Enthalpy of solution}

The enthalpy of solution of various solid forms (in duplicate) was measured at $25^{\circ}, 37^{\circ}$ and $50^{\circ}$. The solid sample (varying from 1.0 to $1.5 \mathrm{mg}$ ) after passing through sieve of mesh size $150 \mu$ was weighed (Sartorius Model CP225D) into a cylindrical glass tube covered with parafilm on one side and was submerged into the ampoule containing $1.5 \mathrm{~mL}$ of acetate buffer $\mathrm{pH} 2.8$ or methanol (the concentration of the resulting solution is $\sim 2 \times 10^{-3} \mathrm{~mol} / 1$ if the weight of the sample is $1 \mathrm{mg}$ ). A plunger with a cap was put from the open end of the tube. The same solvent was put into the reference ampoule. Both ampoules were put into the sample and reference holes of the main block of the calorimeter. The instrument was maintained at constant temperature $\left( \pm 0.005^{\circ}\right)$ during the experiment. The parafilm was shattered mechanically by means of plunger. The performance of the instrument was tested by measuring enthalpy of solution of potassium chloride $(17.231 \mathrm{~kJ} / \mathrm{mol})$ in triple distilled water, which is in good agreement with known enthalpy of solution of $17.322 \mathrm{~kJ} / \mathrm{mol}$. The precision of any individual measurement was better than \pm 0.003 $\mathrm{kJ} / \mathrm{mol}$ for three consecutive experiments.

\section{Heat capacity measurement}

The size of sample used in analysis ranged from 100-150 mg and was weighed (Sartorius Model CP225D) into a glass vial. The empty vial was placed as the reference sample. A temperature step of $2^{\circ}$ is then applied to the system and the heat required is measured. The experiment is then repeated in the reverse direction to verify the measurement. A measurement with empty vial was conducted first to ensure any difference between the heat capacity of the vials is accounted for. The heat capacity was measured at $25^{\circ}\left(24-26^{\circ}\right)$. The performance of the instrument for heat capacity measurement was performed by measuring the heat capacity of sodium chloride $\left(0.866 \mathrm{~J} / \mathrm{g} /{ }^{\circ}\right)$ which was in good agreement with the literature value of 0.854 $\mathrm{J} / \mathrm{g} /{ }^{\circ}$. All the measurements were performed in triplcate.

\section{Aqueous solubility measurement}


MSW-275 (Macro scientific works, New Delhi) shaker was used for measuring aqueous solubility of different forms of efavirenz. Solubility studies were performed by adding $10 \mathrm{mg}$ of sample (passed through sieve of mesh size $150 \mu$ ) in flask containing $10 \mathrm{~mL}$ of acetate buffer $\mathrm{pH} 2.8$. The mixture was shaken at $25^{\circ}, 37^{\circ}$ and $50^{\circ}$ for $24 \mathrm{~h}$. The aliquots (in triplicate) were filtered through $0.45 \mu \mathrm{m}$ membrane filter and analyzed spectrophotometrically at $255 \mathrm{~nm}$. The standard plot of efavirenz was prepared by dissolving a weighed amount of sample in acetate buffer $\mathrm{pH} 2.8$, suitably diluted and absorbance taken at wavelength $255 \mathrm{~nm}$ on a spectrophotometer. $\mathrm{E}^{1 \%}{ }_{1 \mathrm{~cm}}$ was calculated.

\section{Solvent mediated transformation studies}

These experiments were carried out by suspending the polymorphic forms in acetonitrile, methanol and acetate buffer $\mathrm{pH} 2.8$ in a water bath shaker. The suspensions were stirred at $500 \mathrm{rpm}$ at $25^{\circ}$. These suspensions were then filtered under vacuum and the solid phase was analysed for solid state composition by DSC \& XRPD and the results obtained were compared with the starting forms.

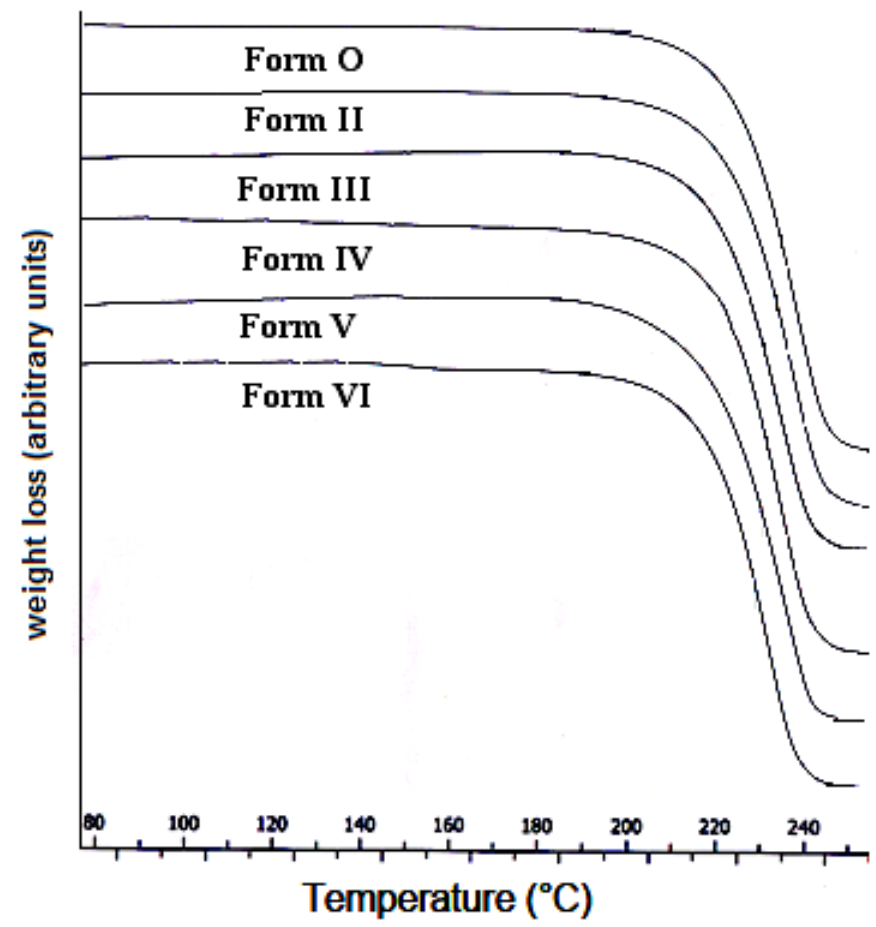

Figure 2a: TGA thermogram of various polymorphic forms of efavirenz.

\section{RESULTS}

\section{Thermal properties of polymorphs}

The thermogravimetric scans as well as their derivative plots for the original sample of efavirenz and all the forms (I-VI) are given in figure $2 \mathrm{a}$ and $2 \mathrm{~b}$. It can be seen that up to $200^{\circ}$ there is no mass loss in any of the sample except for Form VI which shows a very small dip at $\sim 130^{\circ}$ corresponding to non-stoichiometric entrapment of moisture. The temperature corresponding to mass loss is much higher than the boiling point of any of the solvents used in our studies. This clearly indicates that none of the solid form isolated by us is a solvate. Further heating leads to thermal degradation of the molten drug leading to nearly $100 \%$ mass loss. The solid forms were further characterized by DSC. The thermogram (Figure 3) of original sample (Form O) of efavirenz shows a single sharp melting endotherm at $138.81^{\circ}$ (enthalpy of fusion, $\Delta_{\text {fus }} \mathrm{H}=$ $15.22 \mathrm{~kJ} / \mathrm{mol}$ ). Similarly, Form I crystallized from acetonitrile has a single endotherm at $141.35^{\circ}$ $\left(\Delta_{\text {fus }} \mathrm{H}=18.20 \mathrm{~kJ} / \mathrm{mol}\right)$.

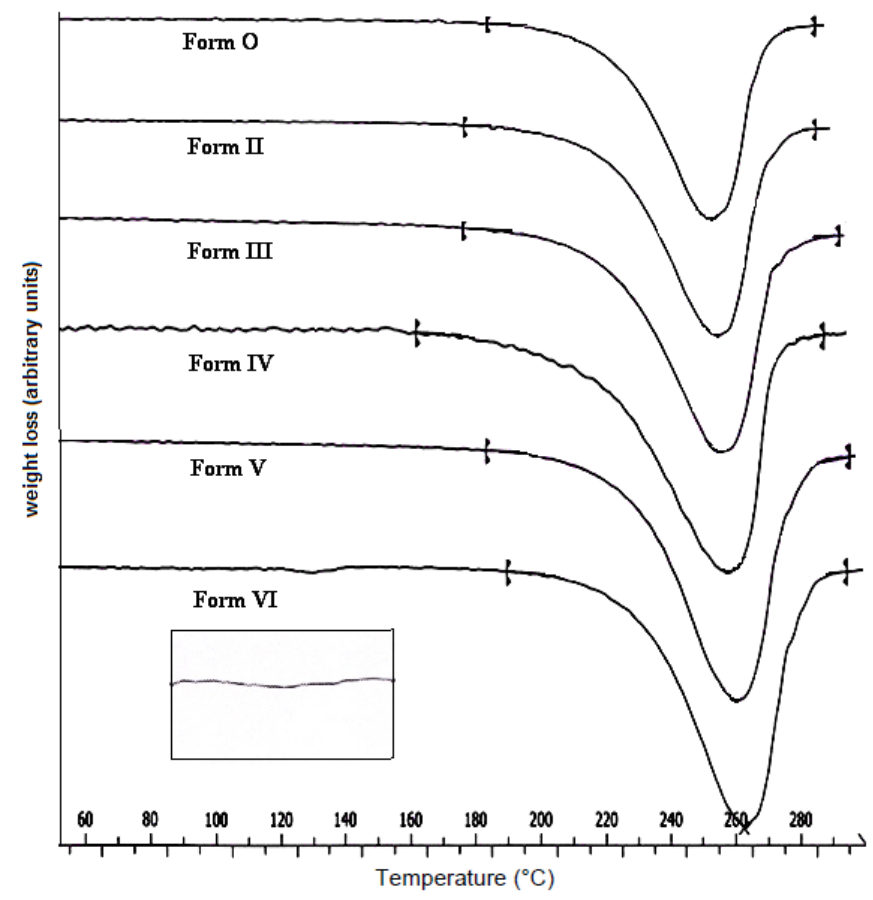

Figure 2b. Derivative TGA thermogram of various polymorphic forms of efavirenz (inset shows enlarged view of small dip appeared in Form VI). 
The DSC thermograms of Forms II (obtained from hexane), III (obtained from methanol), Form IV (obtained from pet ether) and Form V (obtained from n-heptane), show two endotherms separated by an exothermic peak (Figure 3). The presence of two endothermic peaks in the single heating scan is indicative of existence of polymorphism as hydrate or solvate has already been ruled out by thermogravimetric results. The first peak is associated with melting, followed by a small exotherm representing either solid-solid transition or a liquid-solid transition (recrystallization which requires release of energy). As a matter of fact, very low enthalpy of fusion indicates that the low melting point endotherm is immediately or simultaneously accompanied by exothermic

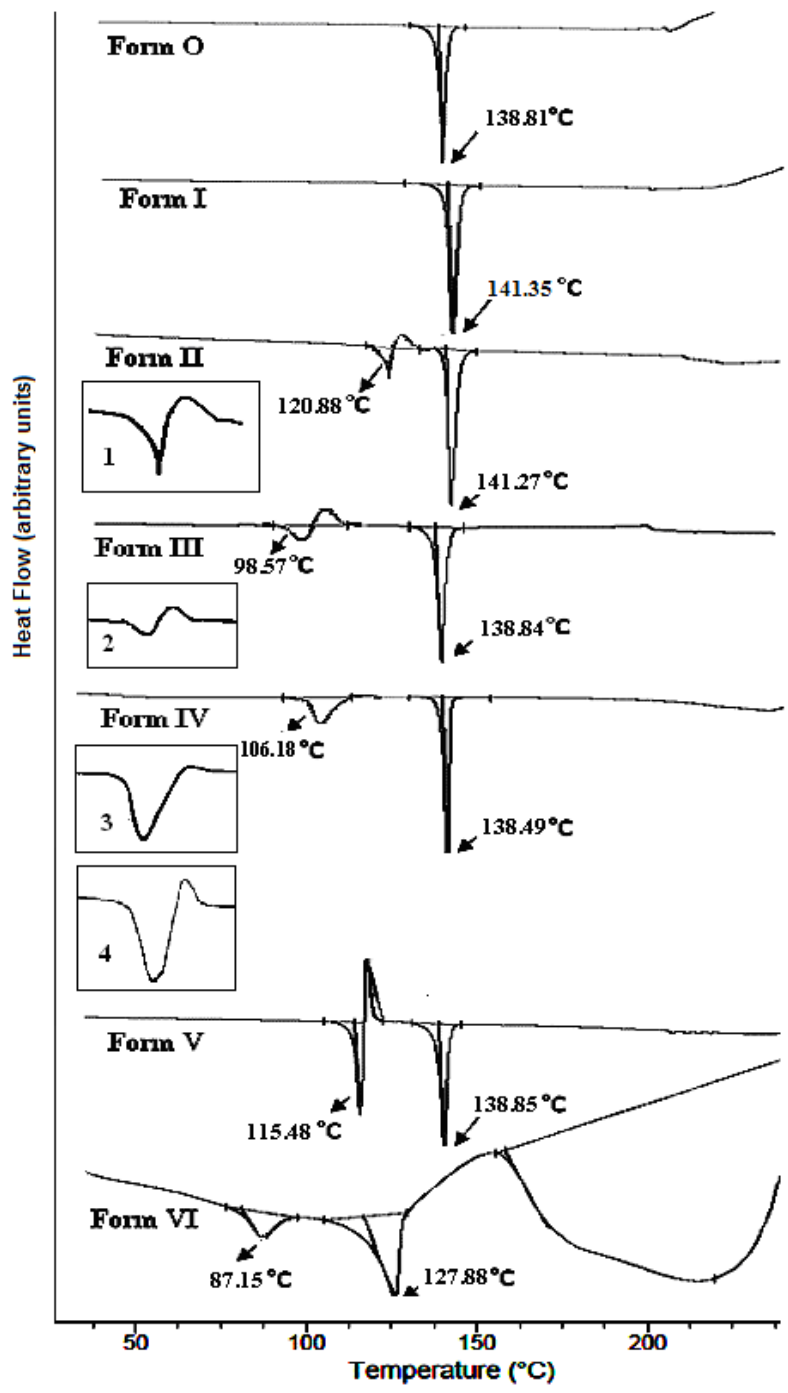

Figure 3. DSC thermogram of lower melting forms of efavirenz (inset 1, 2, 3 are enlarged view of phase transition region as in the full figure; inset 4 shows DSC of Form IV in the same region at $20 \% \mathrm{~min}$ ). crystallization into other polymorphic form. We designate the crystal forms isolated from the solvent by putting the suffix L. After heating them above the temperature of the first endotherm, these are irreversibly converted into different forms and we designate these by putting the suffix $H$. The numerical values of melting temperature for the first endotherm for forms $\mathrm{II}_{\mathrm{L}}-\mathrm{VI}_{\mathrm{L}}$ and their corresponding enthalpy of fusion are given in Table 1 The values of melting temperature for the second endotherm corresponding to melting of forms $\mathrm{II}_{\mathrm{H}}-$ $\mathrm{VI}_{\mathrm{H}}$ along with enthalpy of fusion are also given in the Table 1. The thermogram of Form VI (obtained from THF) differs significantly from the above mentioned forms recording the appearance two endothermic peaks followed by decomposition.

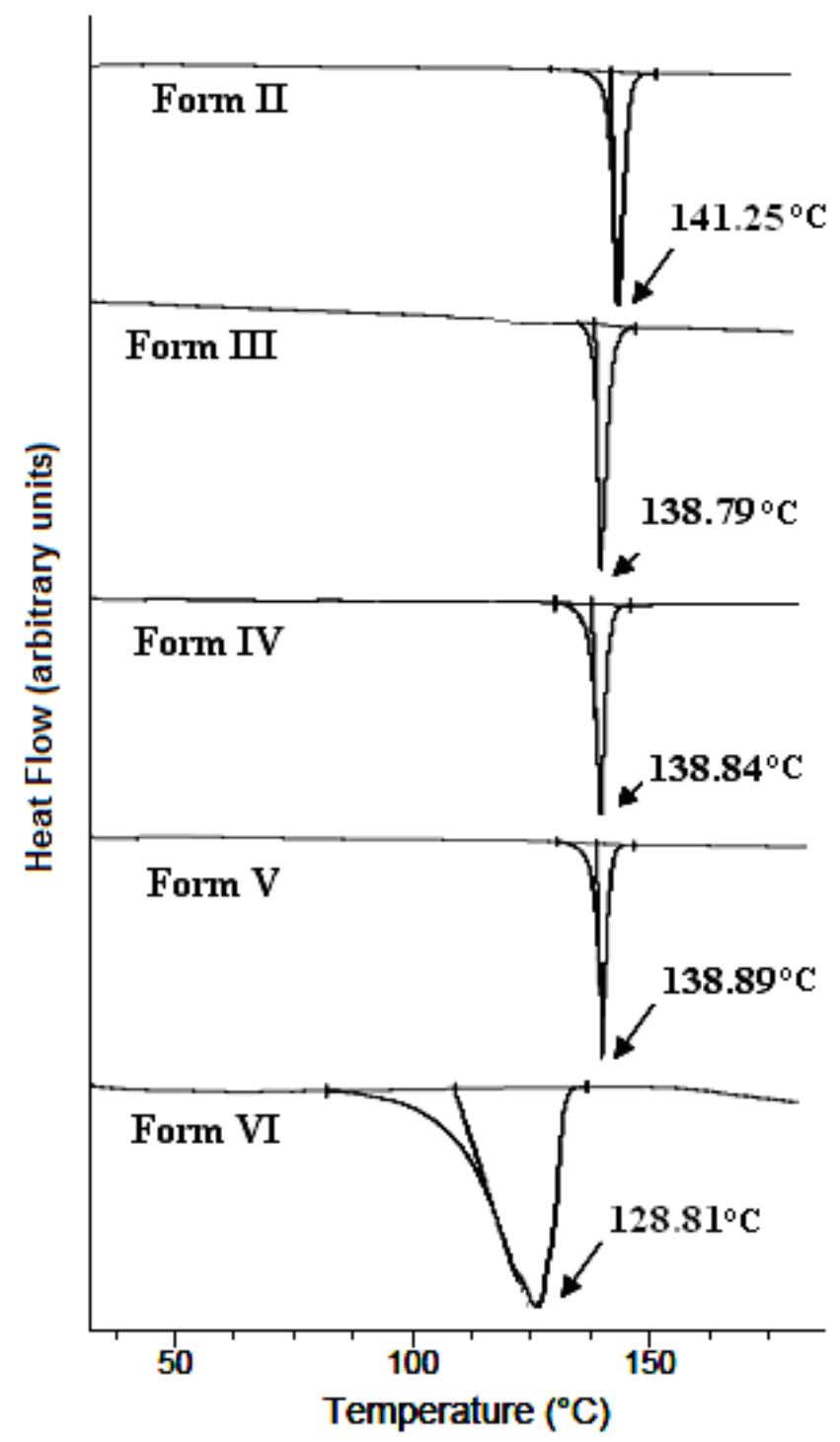

Figure 4. DSC thermogram of higher melting forms of efavirenz. 


\section{Heat induced transformation}

In order to explicitly identify, to which form each of the four lower melting forms has transitioned to upon heating, four different heating experiments were performed. The Form II was heated to $130^{\circ}$ and held at this temperature for $50 \mathrm{~min}$ to ensure complete conversion. Form III was heated to $110^{\circ}$ and Form IV and V were heated to $120^{\circ}$ whereas Form VI was heated to $100^{\circ}$ and held at this temperature for $50 \mathrm{~min}$ to make certain that crystallization to higher melting form is complete. All the samples were cooled to room temperature in a desiccator with zero relative humidity and were subjected to DSC to identify the resulting forms. The DSC traces of these forms showed only a single endotherm, the broad exothermic transition along with the first endotherm is absent (Figure 4).

\section{X-ray powder diffraction}

$\mathrm{X}$-ray powder diffraction pattern of various forms are given in figure $5 \mathrm{a}$ and $5 \mathrm{~b}$. The XRPD pattern of Form $\mathrm{O}$ shows characteristic peaks at $2 \theta=6.07^{\circ}$, $9.5^{\circ}, 10.4^{\circ}, 11.0^{\circ}, 12.3^{\circ}, 13.3^{\circ}, 14.2^{\circ}, 15.1^{\circ}, 16.9^{\circ}$, $19.3^{\circ}, 21.3^{\circ}, 21.8^{\circ}, 23.2^{\circ}, 24.3^{\circ}, 25.0^{\circ}, 27.17^{\circ}$, $28.1^{\circ}, 29.2^{\circ}, 29.7^{\circ}, 30.7^{\circ}, 32.4^{\circ}$ and $37.4^{\circ}$ (Figure $5 \mathrm{a})$. The overlaid XRPD of Form $\mathrm{O}$ and I shows that few new peaks appeared at $12.9^{\circ}, 20.3^{\circ}, 22.65^{\circ}$ and $29.6^{\circ}$ (shown by arrows) in Form I whereas the characteristic peaks of Form $\mathrm{O}$ at $9.5^{\circ}, 15.1^{\circ}$ and $27.17^{\circ}$ (shown by arrows) were absent indicating formation of a new phase. Similarly, a few new peaks at $7.7^{\circ}, 9.3^{\circ}, 24.7^{\circ}$ appeared in Form $\mathrm{II}_{\mathrm{L}}$ whereas peaks at $6.07^{\circ}, 32.4^{\circ}$ and $37.4^{\circ}$ were absent. A new peak at $5.1^{\circ}$ in Form $\mathrm{III}_{\mathrm{L}}$ makes it different from Form $\mathrm{O}$. This form also showed the absence of peaks at $6.07^{\circ}, 13.3^{\circ}, 14.2^{\circ}$ and $30.7^{\circ}$. The XRPD pattern of Form $\mathrm{IV}_{\mathrm{L}}$ showed new peaks at $7.0^{\circ}$ and $14.0^{\circ}$ whereas peaks at $6.07^{\circ}, 10.4^{\circ}$ and $20.1^{\circ}$ were absent. The Form $\mathrm{V}_{\mathrm{L}}$ also showed appearance of peak at $19.2^{\circ}$ other than Form O making it a different crystalline form. The XRPD of the Form $\mathrm{VI}_{\mathrm{L}}$ showed a few new peaks at $12.5^{\circ}$, $13.6^{\circ}, 20.8^{\circ}$ and $25.1^{\circ}$. XRPD scans of higher melting forms $\left(\mathrm{II}_{\mathrm{H}}-\mathrm{VI}_{\mathrm{H}}\right)$ obtained after heating and cooling lower melting forms are given in figure 6. The appearance of new peaks in different forms is highlighted by arrows.

\section{Morphology of polymorphs}

A different crystal habit is formed when the environment of a growing crystal affects its external shape without changing its internal structure (which affects the polymorphism of a crystal) (20). The difference in morphology was confirmed by studying the shape and appearance by scanning electron microscopy (Figure 7). The Form O showed absence of any crystal habit. Morphologically, the Forms I, II and V are basically acicular but there is difference in their sharpness and size. The form I (obtained from acetonitrile) showed sharp and long needle shaped crystals. Form $\mathrm{II}_{\mathrm{L}}$ obtained from hexane also showed small needles while crystals of form $\mathrm{III}_{\mathrm{L}}$ were small irregularly shaped described as anhedral crystals. The crystal habit of Form $\mathrm{IV}_{\mathrm{L}}$ (obtained from pet ether) was found to be bladed while Form $V_{L}$ (obtained from heptane) showed prismatic crystals.

\section{Calorimetric Study}

Solution calorimetry was used to differentiate the various polymorphs by comparing their molar enthalpy of solution (Table 1). The molar enthalpy of solution $\left(\Delta_{\text {sol }} \mathrm{H}\right)$ was determined at $25^{\circ}, 37^{\circ}$ and $50^{\circ}$ in acetate buffer $\mathrm{pH} 2.8$ as the drug is found to be more soluble at this $\mathrm{pH}$ (Table 1). The buffer specific catalysis at this $\mathrm{pH}$ is negligible as rate constant is found to be $3.38 \times 10^{-3}$ day $^{-1}(21)$.

The $\mathrm{pH}$ of the solution was found to be the same after the experiment is over. All the forms except form I $\left(\Delta_{\text {sol }} \mathrm{H}=2.62 \mathrm{~kJ} / \mathrm{mol}\right.$ at $\left.25^{\circ}\right)$ showed exothermic dissolution (Figure 8) in acetate buffer ( $\mathrm{pH} 2.8$ ) and the absolute value of molar enthalpy of solution followed the order: Form $\mathrm{IV}_{\mathrm{L}}<$ Form $\mathrm{V}_{\mathrm{L}}<$ Form $\mathrm{II}_{\mathrm{L}}<$ Form $\mathrm{III}_{\mathrm{L}}<$ Form $\mathrm{VI}_{\mathrm{L}}$. The molar enthalpy of solution decreased with increase in the temperature (Table 1). The enthalpy of solution was also determined for the high melting forms $\left(\mathrm{II}_{\mathrm{H}}\right.$, $\mathrm{III}_{\mathrm{H}}, \mathrm{IV}_{\mathrm{H}}, \mathrm{V}_{\mathrm{H}}$ and $\mathrm{VI}_{\mathrm{H}}$ ). The Form $\mathrm{II}_{\mathrm{H}}$ behaved endothermically while other high melting forms $\left(\mathrm{III}_{\mathrm{H}}, \mathrm{IV}_{\mathrm{H}}, \mathrm{V}_{\mathrm{H}}\right.$ and $\mathrm{VI}_{\mathrm{H}}$ ) were found to be less exothermic than their corresponding low melting forms at all the temperatures.

The numerical value of enthalpy of solution depends upon the nature of the solvent; however, the value of enthalpy of transition is independent of the solvent as for all the forms the enthalpy of solvation is same in a particular solvent. The enthalpy of solution was also determined in methanol. All the forms showed endothermic enthalpy of solution with the same order as in acetate buffer $\mathrm{pH} 2.8$ (Table 1). It is clear from table 1 that the difference between the enthalpy of solution of all the forms in both the solvents is same 
Table 1. Melting temperature, enthalpy of fusion, solubility, enthalpy of solution and molar heat capacity of lower and higher melting forms of efavirenz

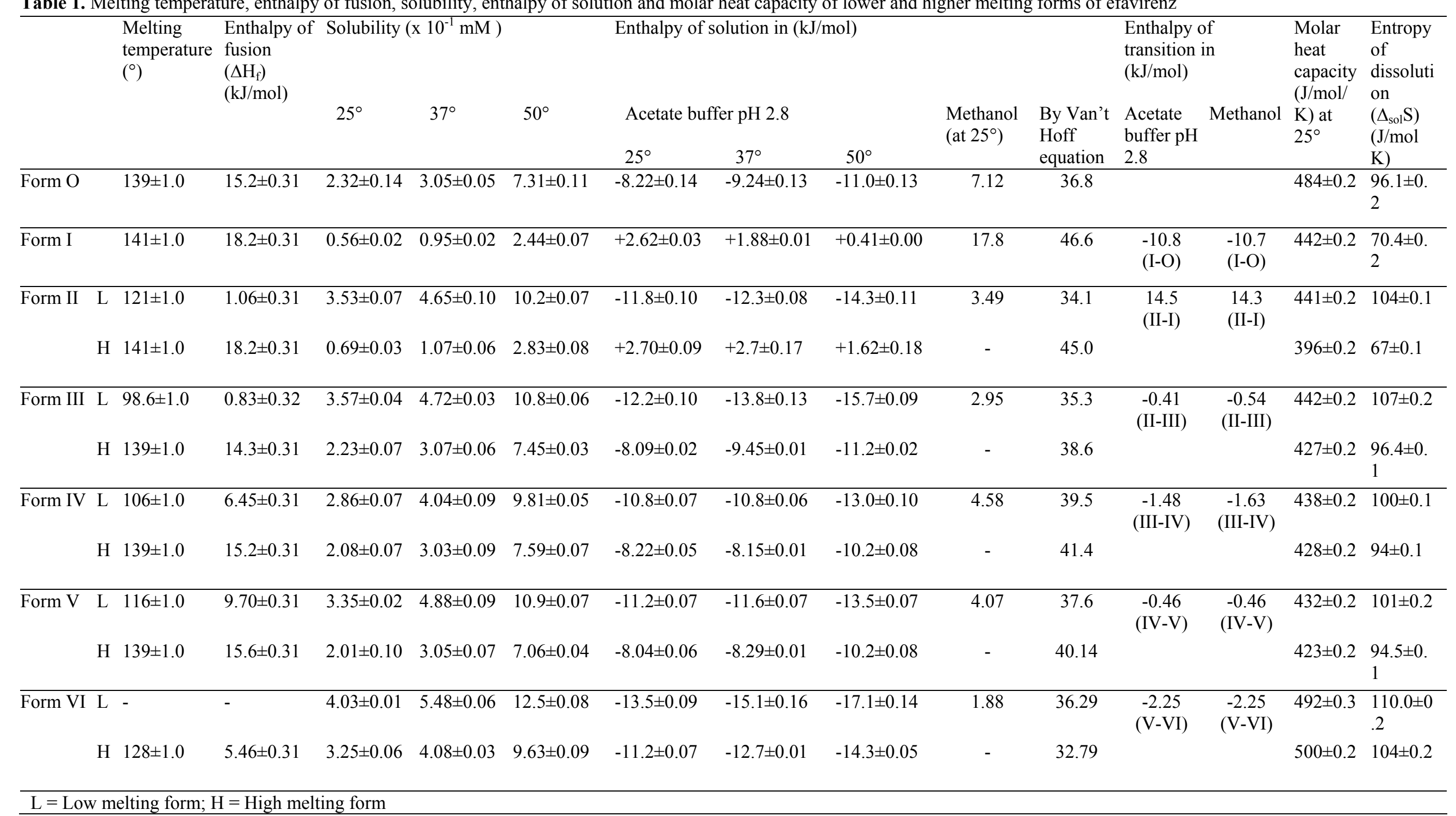




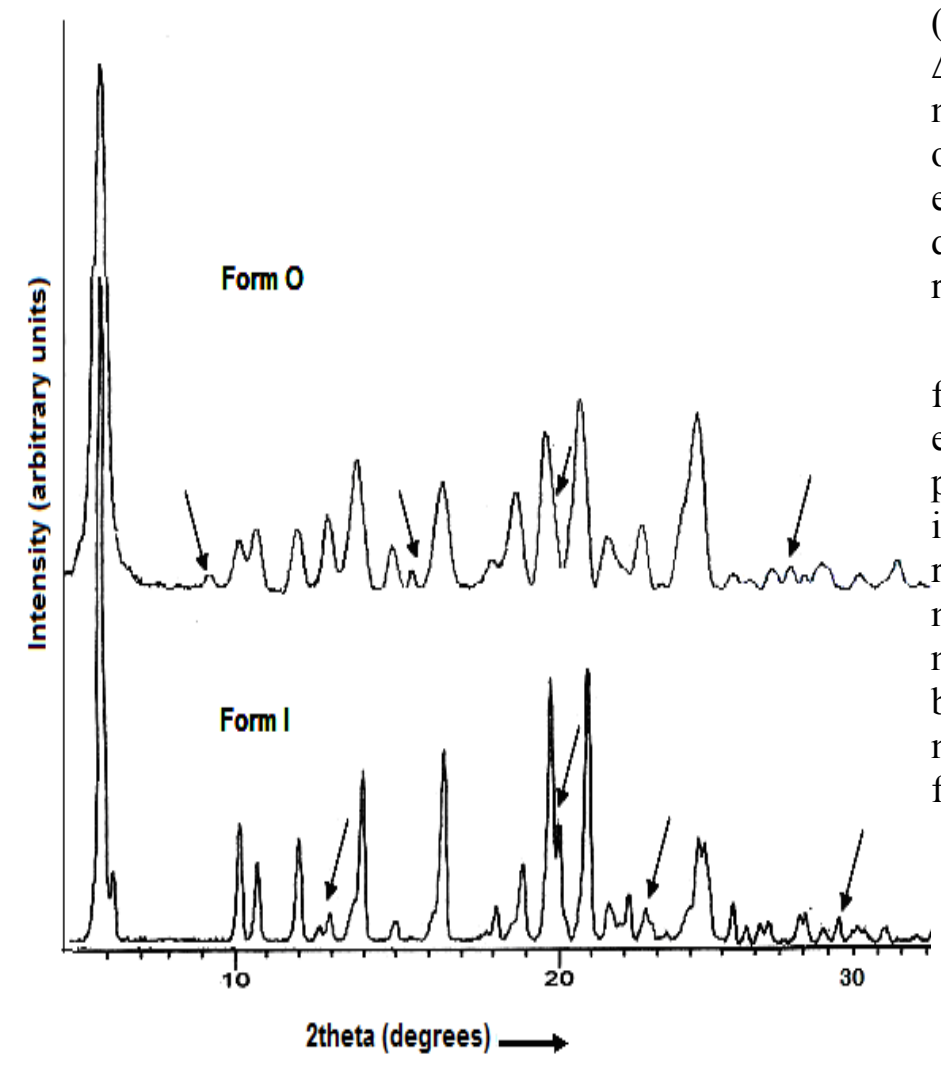

Figure 5a. XRPD of Form $\mathrm{O}$ and Form I of efavirenz.

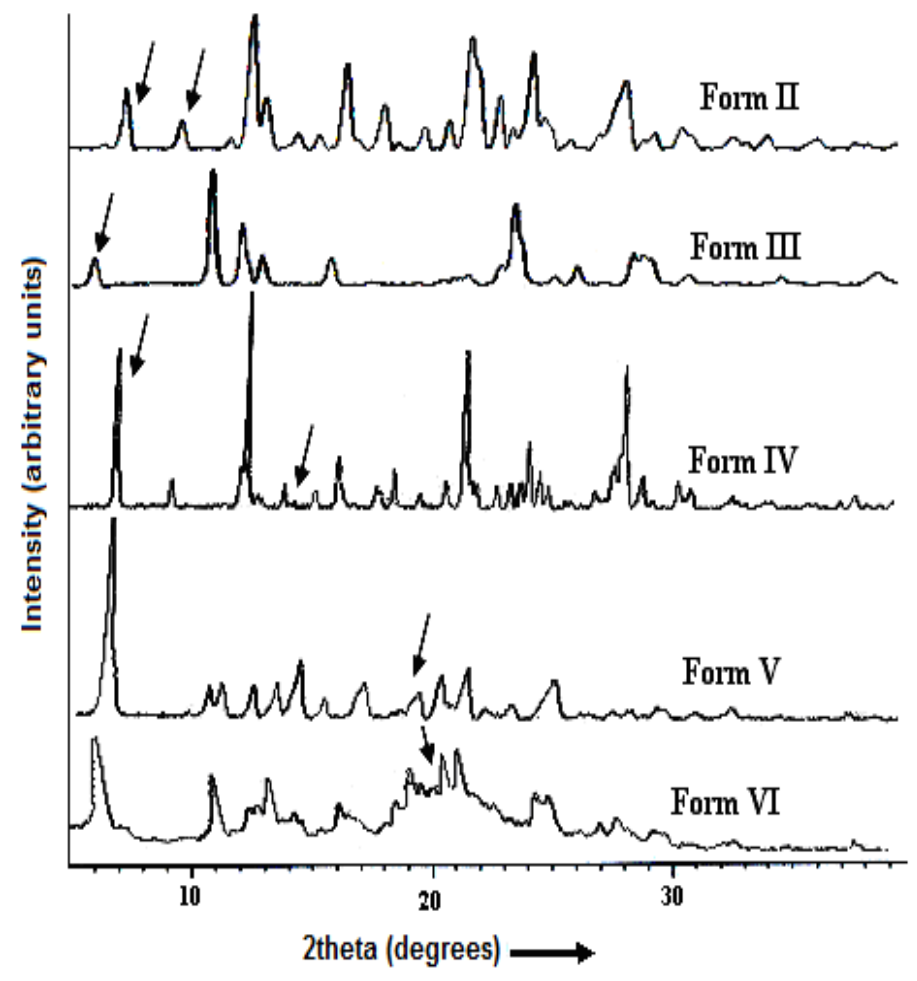

Figure 5b. XRPD of lower melting forms $\left(\mathrm{II}_{\mathrm{L}}-\mathrm{VI}_{\mathrm{L}}\right)$ of efavirenz.
$(15.24 \pm 0.08 \mathrm{~kJ} / \mathrm{mol})$. The plot (Figure 9) between $\Delta_{\text {sol }} \mathrm{H}$ in acetate buffer $(\mathrm{pH} 2.8)$ versus $\Delta_{\text {sol }} \mathrm{H}$ in methanol is a straight line indicating high accuracy of the calorimetric values. The Van't Hoff enthalpies are also given in the table I but these differ a lot from the calorimetric values and are less reliable.

The heat capacity of low and high melting forms has also been determined as it is useful for estimation of transition temperature of polymorphic pair. The molar heat capacity of Form $\mathrm{O}$ and Form I is found to be $484.02 \mathrm{~J} / \mathrm{mol} / \mathrm{K}$ and $442.34 \mathrm{~J} / \mathrm{mol} / \mathrm{K}$ respectively. The molar heat capacity of low melting Forms ( $\mathrm{II}_{\mathrm{L}}, \mathrm{III}_{\mathrm{L}} \mathrm{IV}_{\mathrm{L}}$ and $\mathrm{V}_{\mathrm{L}}$ ) and high melting forms (Form $\mathrm{II}_{\mathrm{H}}, \mathrm{III}_{\mathrm{H}}, \mathrm{IV}_{\mathrm{H}}$ and $\mathrm{V}_{\mathrm{H}}$ ) have been determined at $25^{\circ}$ and is given in table 1 . The molar heat capacity of low melting metastable forms is higher as compared to high melting forms.

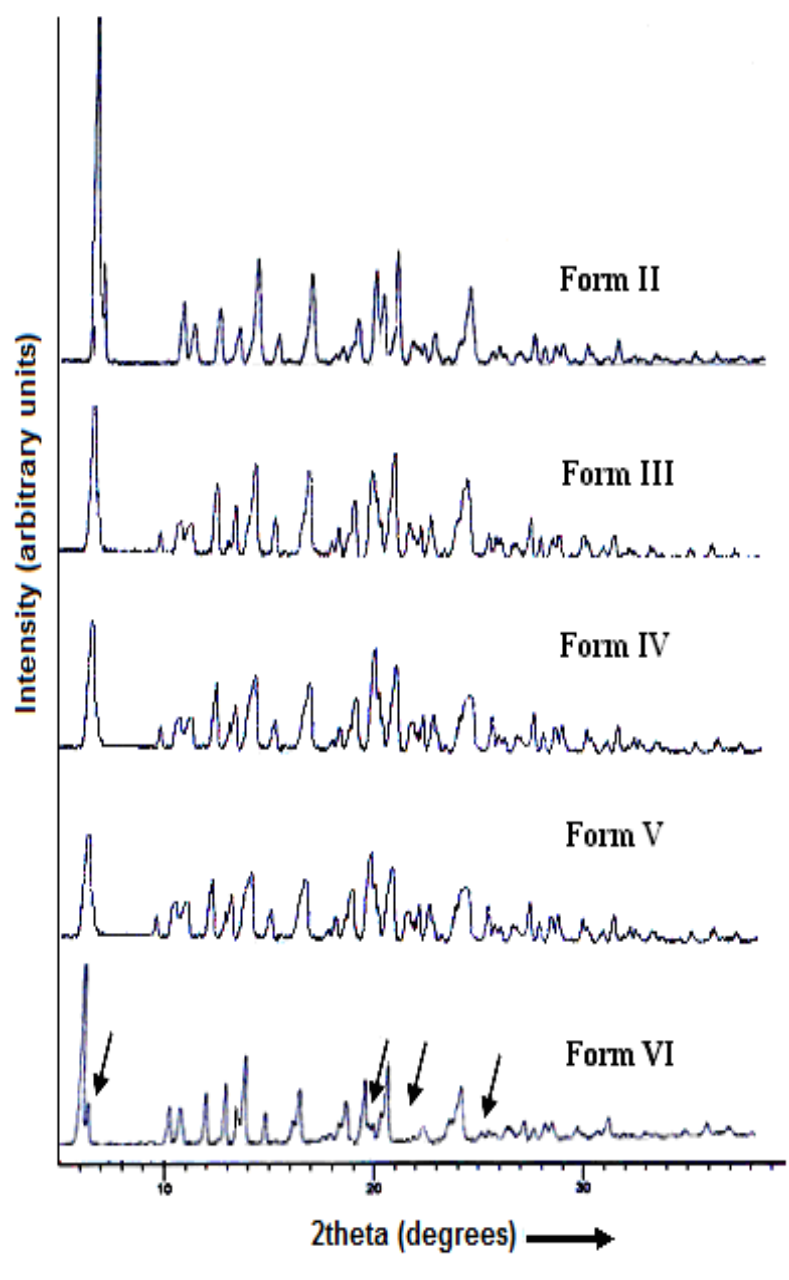

Figure 6. XRPD of higher melting forms $\left(\mathrm{II}_{\mathrm{H}}-\mathrm{VI}_{\mathrm{H}}\right)$ of efavirenz. 


\section{Solubility study}

Solubilities of Form O, Form I, low melting (Form $\mathrm{II}_{\mathrm{L}}, \mathrm{III}_{\mathrm{L}} \mathrm{IV}_{\mathrm{L}}$ and $\mathrm{V}_{\mathrm{L}}$ ) and high melting (Form $\mathrm{II}_{\mathrm{H}}$, $\mathrm{III}_{\mathrm{H}}, \mathrm{IV}_{\mathrm{H}}$ and $\mathrm{V}_{\mathrm{H}}$ ) forms were determined and then compared statistically using the tukey's test. Solubility data in acetate buffer $(\mathrm{pH} 2.8)$ at $25^{\circ}, 37^{\circ}$ and $50^{\circ}$ are given in Table 1 . The solubility study suggests that the Form I is least soluble while Form VI obtained from THF is most soluble with a $\sim 1.8$ times increase in solubility as compared to Form $\mathrm{O}$ (Table I).

The solid in equilibrium with the solution was subjected to characterization by DSC and XRPD and the results were found to be the same as that of the starting material. The solubility and enthalpy of solution data were used to determine the entropy of dissolution utilizing equations:

$$
\begin{aligned}
& \Delta_{\text {sol }} \mathbf{G}=-\mathbf{R T} \operatorname{Tn} \mathbf{s} \ldots \ldots \\
& \Delta_{\text {sol }} \mathbf{H}=\Delta_{\text {sol }} \mathbf{G}+\mathbf{T} \Delta_{\text {sol }} \mathbf{S}
\end{aligned}
$$

where $\mathrm{s}$ is the solubility of the particular polymorphic form

The values of $\Delta_{\text {sol }} \mathrm{S}$ are positive and the magnitude is very high. The average of the entropy of dissolution at the three temperatures $\left(25^{\circ}, 37^{\circ}, 50^{\circ}\right)$ is given in table 1 .

The enthalpy of solution and the solubility data are also utilized to determine the thermodynamic relationship between polymorphic pairs.

\section{Solvent mediated transformation}

The solvent mediated transformation experiments of various low melting forms were performed at $25^{\circ}$ in acetonitrile, methanol and acetate buffer $\mathrm{pH} 2.8$ (Table 2). The forms crystallized from saturated solution of acetonitrile indicate the transformation of Form $\mathrm{O}$ and the metastable polymorphs to stable Form I. However, this transformation only occurs in acetonitrile. The analysis of forms recovered after suspending in methanol revealed that only form $\mathrm{VI}_{\mathrm{L}}$ undergo transformation into Form $\mathrm{III}_{\mathrm{L}}$ within 1 day with no further transformation after 3 days whereas the forms $\mathrm{O}, \mathrm{I}_{\mathrm{I}} \mathrm{II}_{\mathrm{L}}, \mathrm{II}_{\mathrm{L}}, \mathrm{IV}_{\mathrm{L}}$ and $\mathrm{V}_{\mathrm{L}}$ remained intact with no transformation even after 3 days. All the forms were found to be stable in acetate buffer $\mathrm{pH}$ 2.8 .

\section{DISCUSSION}

The comparison of DSC scans of Form I which is obtained as long needles with that of original sample (Form O) which has no particular crystal habit shows differences in the melting temperatures (138.81 ${ }^{\circ}$ for Form $\mathrm{O}$ and $141.35^{\circ}$ for Form I) and enthalpy of fusion $(15.22 \mathrm{~kJ} / \mathrm{mol}$ for Form $\mathrm{O}$ and $18.20 \mathrm{~kJ} / \mathrm{mol}$ for Form I) suggesting them to be different forms. Besides this, differences in the diffraction profiles are evident for what concerns
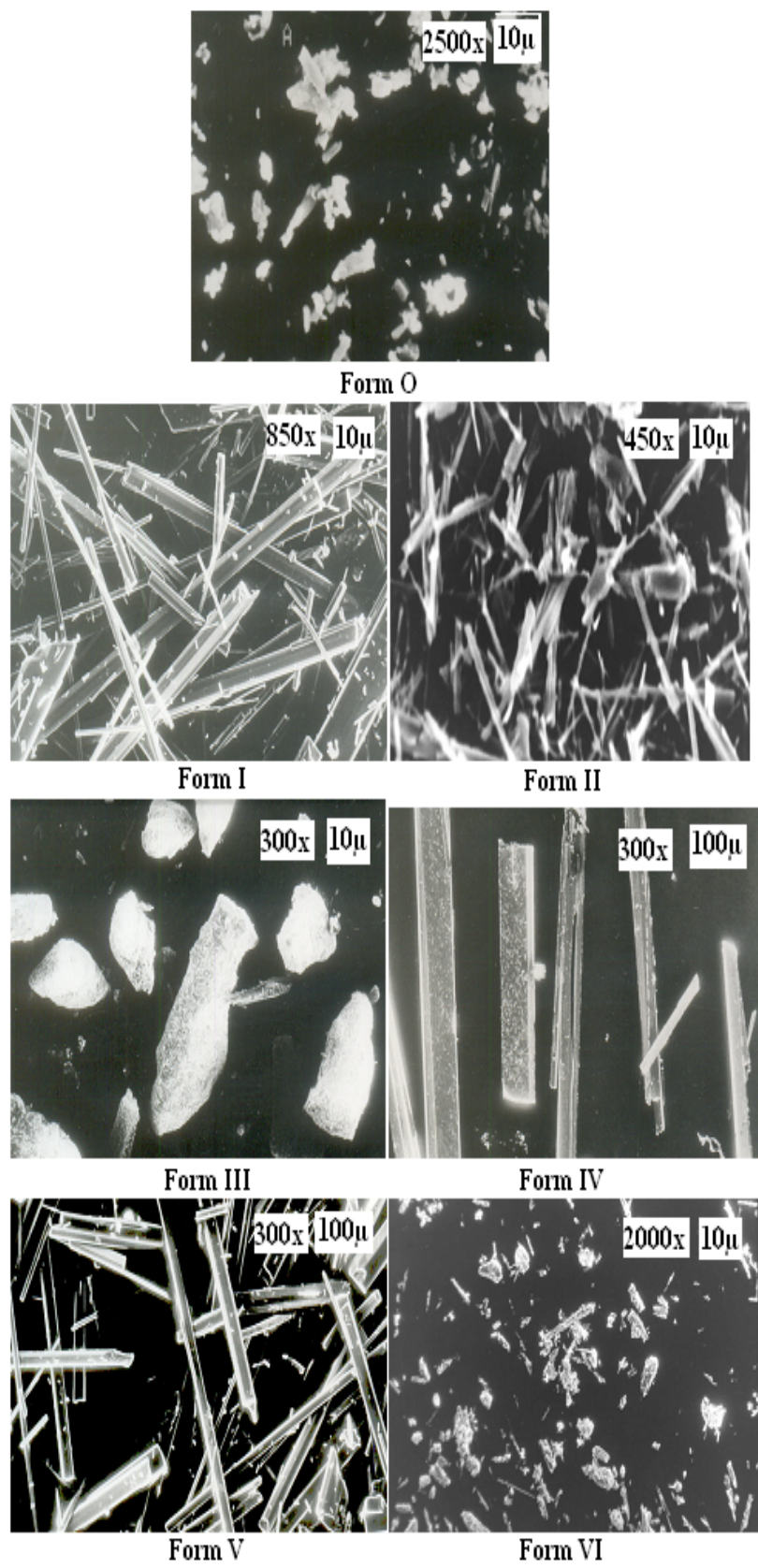

Figure 7. Scanning electron micrograph of polymorphs of efavirenz. 


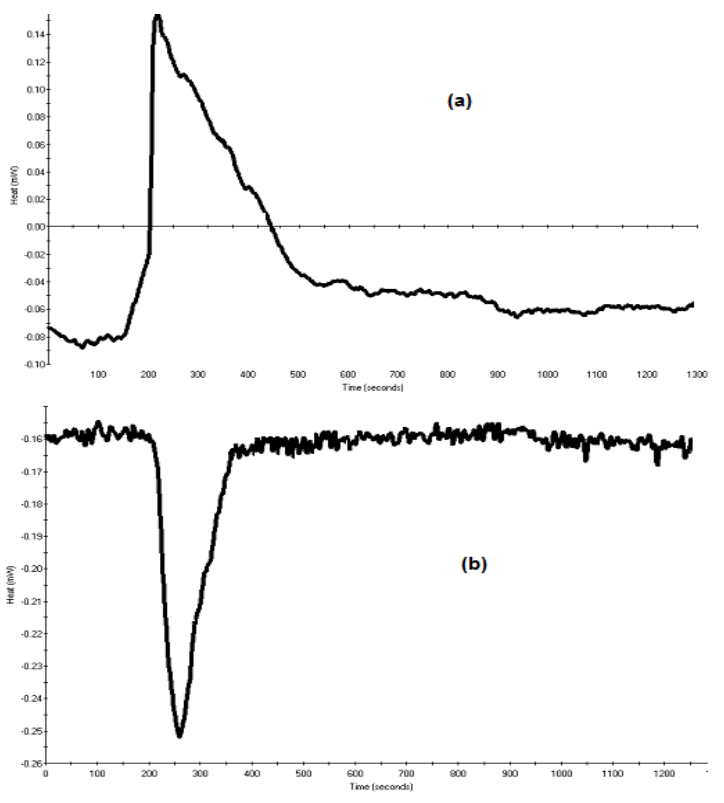

Figure 8. Representative graphs of enthalpy of solution in acetate buffer $\mathrm{pH} 2.8$ of (a) Form $\mathrm{II}_{\mathrm{L}}$ (b) Form $\mathrm{II}_{\mathrm{H}}$.

both peak position and peak broadening. It is evident in Figure 5a (normalized to same scale) that the peaks are sharper in Form I indicating its more crystalline nature whereas Form $\mathrm{O}$ appears to be a less ordered state. The intensity of peak corresponding to $100 \%$ relative intensity in terms of number of counts also shows that Form I (8786 cts) is more crystalline than Form O (4899 cts). Also the appearance of few new peaks $\left(12.9^{\circ}\right.$, $20.3^{\circ}, 22.65^{\circ}$ and $29.6^{\circ}$ ) in Form I and absence of two of the peaks present in Form O makes this form different from Form O. Moreover, their solubility and enthalpy of solution (Table 1) also indicate that these are quite distinct forms. The enthalpy of solution for Form $\mathrm{O}$ was found to be exothermic incomparison to Form I which is found to be endothermic indicating different crystalline forms. These differences can not be attributed to particle size differences as these forms were sieved through

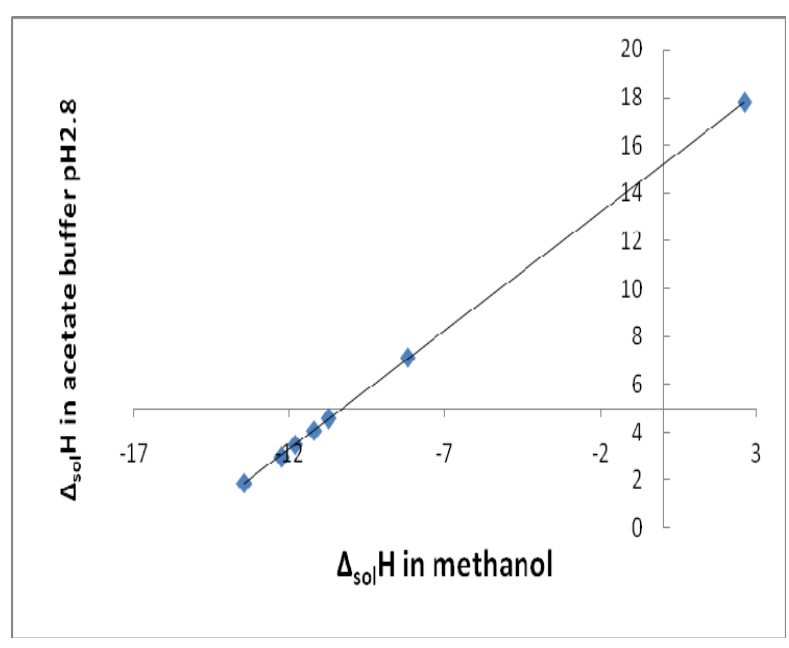

Figure 9. Plot of enthalpy of solution of various forms of efavirenz in acetate biffer $\mathrm{pH} 2.8$ and in methanol

a mesh size of $150 \mu$ before measuring both these parameters. The higher numerical value of melting temperature and enthalpy of fusion suggest that Form I is thermodynamically more stable than Form O.

The details of DSC scans very well depict that Form II undergoes endo-exo effect at $120.8^{\circ}$ followed by a sharp endothermal effect at $141.3^{\circ}$ (Figure 3). This exothermic peak arises because the crystals of the higher melting form grow from the melt of lower melting form. The melting temperature and heat of fusion of the higher melting (Form $\mathrm{II}_{\mathrm{H}}$ ) is similar to the heat of fusion of Form I suggesting that Form $\mathrm{II}_{\mathrm{L}}$ might have converted to Form I after melting. This is supported by their solubility and enthalpy of solution data (Table 1). Similar behavior was observed in the DSC traces of Forms III, Form IV and Form V. All these forms depicted a small endotherm immediately succeeded by an exotherm (Figure 4) which is not

\begin{tabular}{|c|c|c|c|c|c|c|}
\hline \multirow{2}{*}{ Initial polymorph } & \multicolumn{2}{|l|}{ Acetonitrile } & \multicolumn{2}{|l|}{ Methanol } & \multicolumn{2}{|c|}{ Acetate buffer $\mathrm{pH} 2.8$} \\
\hline & 1 day stirring & 3 day stirring & 1 day stirring & 3 day stirring & 7 day stirring & 15 day stirring \\
\hline Form $\mathrm{O}$ & I & I & $\mathrm{O}$ & $\mathrm{O}$ & $\mathrm{O}$ & $\mathrm{O}$ \\
\hline Form I & I & I & I & I & I & I \\
\hline Form $\mathrm{II}_{\mathrm{L}}$ & I & I & $\mathrm{II}_{\mathrm{L}}$ & $\mathrm{II}_{\mathrm{L}}$ & $\mathrm{II}_{\mathrm{L}}$ & $\mathrm{II}_{\mathrm{L}}$ \\
\hline Form $\mathrm{III}_{\mathrm{L}}$ & I & I & $\mathrm{III}_{\mathrm{L}}$ & $\mathrm{III}_{\mathrm{L}}$ & $\mathrm{III}_{\mathrm{L}}$ & $\mathrm{III}_{\mathrm{L}}$ \\
\hline Form $\mathrm{IV}_{\mathrm{L}}$ & $\mathrm{IV}_{\mathrm{L}}$ & I & $\mathrm{IV}_{\mathrm{L}}$ & $\mathrm{IV}_{\mathrm{L}}$ & $\mathrm{IV}_{\mathrm{L}}$ & $\mathrm{IV}_{\mathrm{L}}$ \\
\hline Form $\mathrm{V}_{\mathrm{L}}$ & $\mathrm{V}_{\mathrm{L}}$ & I & $\mathrm{V}_{\mathrm{L}}$ & $\mathrm{V}_{\mathrm{L}}$ & $\mathrm{V}_{\mathrm{L}}$ & $\mathrm{V}_{\mathrm{L}}$ \\
\hline Form $\mathrm{VI}_{\mathrm{L}}$ & I & I & $\mathrm{III}_{\mathrm{L}}$ & $\mathrm{III}_{\mathrm{L}}$ & $\mathrm{O}$ & $\mathrm{O}$ \\
\hline
\end{tabular}


accompanied by any mass loss in TGA suggesting these forms to be new polymorphic forms which are also metastable forms and convert to higher melting forms upon heating. In case of Form IV, the exotherm succeeding the endotherm is not very sharp. The higher rates are used in DSC to overcome the transition rate kinetics, so the DSC of Form IV was performed at $20 \%$ min (Figure 3). This DSC scan shows a clear exothermic peak suggesting the solid-liquid transition for conversion of Form $\mathrm{IV}_{\mathrm{L}}$ to Form $\mathrm{IV}_{\mathrm{H}}$. The DSC scan of Form VI is found to be different from other forms as there is a large shift in the DSC baseline which can be attributed to poor crystalline nature of this form. A very small dip is shown in TGA suggesting a nonstoichiometric entrapment of THF which might have been taken up by this form during its preparation from the solvent. But this entrapment is very small and can be neglected. However, an endothermic peak at $87.15^{\circ}$ suggests a solid-solid transition which is then converted to the form melting at $127.88^{\circ}\left(\mathrm{VI}_{\mathrm{H}}\right)$ with enthalpy of fusion amounting to $5.46 \mathrm{~kJ} / \mathrm{mol}$. Very small numerical value of $\Delta \mathrm{H}_{\mathrm{f}}$ and a broad melting of this form $\left(\mathrm{VI}_{\mathrm{H}}\right)$ is also suggestive of its least crystalline nature among all the high melting forms. The exothermic transition depicting recrystallization present in the other forms (Form II, III, IV and V) was absent in this form.

At this stage, the primary interest lies in determining whether the polymorphic pairs are enantiotropically or monotropically related. In terms of stability, determination of whether the forms are monotropic or enantiotropic is of considerable benefit; as such knowledge will theoretically aid the formulator in determining the likely stability of the material at any stated temperature $(22,23)$. As can be seen in Table 1, the stable Forms $\mathrm{II}_{\mathrm{H}}-\mathrm{V}_{\mathrm{H}}$ obtained after phase-phase transition (liquid-solid) of Forms $\mathrm{II}_{\mathrm{L}}-\mathrm{V}_{\mathrm{L}}$ respectively show higher melting temperature and higher enthalpy of fusion suggesting them to be monotropically related according to the Burger's rule which states that "if the higher melting form has lower heat of fusion, the two forms are usually enantiotropic, otherwise they are monotropic". Besides this, many authors have reported an exothermic transition corresponding to the conversion of lower melting form to a higher melting form and concluding these forms to be monotropic (according to heat of transition rule) $(24,25)$. The heat of fusion rule cannot be applied to Form VI as the first endotherm might not be melting, so form $\mathrm{VI}_{\mathrm{L}} / \mathrm{VI}_{\mathrm{H}}$ must be enantiotropically related, whereas, forms $\mathrm{I} / \mathrm{O}, \mathrm{VI}_{\mathrm{H}} / \mathrm{O}$ and $\mathrm{VI}_{\mathrm{H}} / \mathrm{I}$ represents a monpotropic relationship. As the thermodynamic relationship between $\mathrm{VI}_{\mathrm{L}}$ and $\mathrm{VI}_{\mathrm{H}}$ is enantiotropic, the transition $\mathrm{VI}_{\mathrm{L}}$ to $\mathrm{VI}_{\mathrm{H}}$ can either be thermodynamically reversible or irreversible. Although Form $\mathrm{VI}_{\mathrm{L}}$ converts to $\mathrm{VI}_{\mathrm{H}}$ on heating this form does not convert back to $\mathrm{VI}_{\mathrm{H}}$ on cooling. The apparent lack of reversibility shows these to be irreversible enantiotrophs.

In order to further support our observation that different forms are monotropically related and to confirm their kinetic irreversibility, the Forms $\mathrm{II}_{\mathrm{L}}$, $\mathrm{III}_{\mathrm{L}}, \mathrm{IV}_{\mathrm{L}}$, and $\mathrm{V}_{\mathrm{L}}$ were heated on a DSC furnace just above the end of the crystallization exotherm, cooled to room temperature $\left(28^{\circ}\right)$ and heated again to the melting point. It was observed that the first endotherm disappeared in the DSC graph of the repeated heating curve (Figure 3). The first endotherm as well as exotherm corresponding to metastable form does not appear in the DSC scan even after 7 days. From the heating-cooling DSC experiments, it is clear that the transition is irreversible suggesting the existence of monotropy between low melting and high melting forms $\left(\mathrm{II}_{\mathrm{L}}\right.$, $\mathrm{III}_{\mathrm{L}}, \mathrm{IV}_{\mathrm{L}}$, and $\mathrm{V}_{\mathrm{L}}$ ).

The direct comparison of our results with the literature could not be performed because of lack of similarity in the experimental conditions. The comparison of the metastable form prepared by recrystallization from petroleum ether $\left(\right.$ Form $\left.I_{\mathrm{L}}\right)$ with literature reveals that the reported form is recrystallized when pet ether is used as anti solvent and the DSC pattern shows three endotherms, in contrast to two endotherms separated by exotherm in our results (14). It is not mentioned in the literature whether the first endotherm is desolvation or melting. Besides this, the Form $\mathrm{V}$ obtained from heptane seems to be similar to a form reported by Radesca et al (12). The DSC curve matches with ours, but the workers have not calculated the virtual transition temperature and other thermodynamic parameters. Similarly, no reports are available for comparison of Form VI obtained from THF because the previous workers have used small percentage of THF along with heptane to crystallize out the polymorphic form which is different from ours (12).

Furthermore, a comparison of the forms prepared by us with those of US patent 6673372 shows that the solvent systems as well as experimental conditions are different (13). Form I, is recrystallized by us from acetonitrile by us while it is recrystallized from a mixture of heptane and 
THF in the US patent. We agree that the DSC and XRPD are quite similar but there is a small additional peaks in the XRPD (ours) with intensity $\sim 10 \%$ which may be due to some impurity or imperfection or due to the existence of a different form other than reported by US patent. Moreover, the melting point of Form I prepared by us is higher than the melting point of Form I in patent. The presence of impurities lowers the melting point and thus the probability of impurities in the Form I reported in the patent can also not be ruled out. Comparison of DSC of Form II in present study with that in patent some difference in the position of first melting endotherm is observed but the XRPD patterns are quite different. Besides this, this form is obtained by recrystallization from hexane at room temperature after 10 days whereas in US patent it is obtained from heptane at $70-80^{\circ}$ and then cooling by contact with cool surface. These differences suggest that Form II is not the same as that reported in US patent. The DSC and XRPD of Form III are clearly different from those reported in the current manuscript. The Form IV, it is obtained by recrystallization from petroleum ether in the current work and from a mixture of heptane and 1$10 \%$ THF in the patent. The melting point at the first endotherm is at $120^{\circ}$ in our studies and at $74.1^{\circ}$ in patent which is quite different suggesting the two forms to be different. Thus all the forms except Form I appear to be different from that reported in US patent (13).

X-ray powder diffraction pattern of all the forms show distinct differences in the position of the peaks of various forms clearly indicating different crystal lattices of all the polymorphic forms (Figure 5). The relative intensity of the peaks in Form $\mathrm{VI}_{\mathrm{L}}$ is much lower suggesting the less crystalline nature of this form. The XRPD pattern of heat treated Form $\mathrm{II}_{\mathrm{H}}$ is different from that of Form $\mathrm{II}_{\mathrm{L}}$ and resembles that of Form I. This supports the observation made by DSC that Form $\mathrm{II}_{\mathrm{L}}$ is converted to Form I. The comparison of figures 5 and 6 shows that XRPD of higher forms $\left(\mathrm{III}_{\mathrm{H}}-\mathrm{V}_{\mathrm{H}}\right)$ do not match with the lower melting forms $\left(\mathrm{III}_{\mathrm{L}}-\mathrm{V}_{\mathrm{L}}\right)$. No doubt the XRPD patterns of Forms $\mathrm{III}_{\mathrm{H}}-\mathrm{V}_{\mathrm{H}}$ are similar to that of Form $\mathrm{O}$ suggesting the conversion of metastable Forms $\mathrm{III}_{\mathrm{L}^{-}}$ $\mathrm{V}_{\mathrm{L}}$ to stable Form $\mathrm{O}$ after being treated by heat. However, the new peaks are appearing at $20.5^{\circ}$, $20.9^{\circ}, 21.6^{\circ}$ and $23.0^{\circ}$ in the XRPD pattern of heat treated Form $\mathrm{VI}_{\mathrm{L}}$ (Form $\mathrm{VI}_{\mathrm{H}}$ ). The figure 6 showing the XRPD of high melting forms is normalized to the same scale on y-axis. The less crystalline nature of Form $\mathrm{VI}_{\mathrm{H}}$ is clearly visible. Moreover, there is a small shift in the position of some of the peaks. All these observations suggest it to be completely different new polymorphic form of efavirenz.

The relationship of the various forms in term of their thermal behavior and conversions is summarized in scheme 1. The double headed arrows are used to indicate similarity between $\mathrm{III}_{\mathrm{H}}$, $\mathrm{IV}_{\mathrm{H}}, \mathrm{V}_{\mathrm{H}}$ and $\mathrm{O}$ as well as between Form $\mathrm{II}_{\mathrm{H}}$ and $\mathrm{I}$ whereas Form $\mathrm{VI}_{\mathrm{H}}$ is different from all these forms.

In the present study the technique of solution calorimetry has allowed the characterization of polymorphic forms through accurate determination of enthalpy of solution of each form in a particular solvent. Solution calorimetry approach works on the basis that the enthalpy of solution is closely associated with the lattice energy. The enthalpy of solution will be different for different forms. If a compound exists in two or more forms with different lattice energy, the enthalpy of solution in a common solvent will differ (26) as is given in table 1. The enthalpy of transition of polymorphic forms estimated from enthalpy of solution has been found to be similar in both the solvents. This All the low melting and high melting forms were found to be exothermic in acetate buffer $\mathrm{pH} 2.8$ except form I. The endothermic $\Delta_{\text {sol }} \mathrm{H}$ associated with form I indicates the most crystalline nature of this form. Among all other forms, the numerical value of Form $\mathrm{VI}_{\mathrm{L}}$ was found to highest exothermic $\Delta_{\text {sol }} \mathrm{H}$ suggesting this form to be least crystalline. The lowest $\Delta_{\text {sol }} \mathrm{H}$ for Form $\mathrm{VI}_{\mathrm{L}}$ indicates this form to be least crystalline and this is very well co related with XRPD studies which depicts the semi-crystalline nature of Form $\mathrm{VI}_{\mathrm{L}}$. Interestingly, the molar enthalpy of solution of Form $\mathrm{I}$ and Form $\mathrm{II}_{\mathrm{H}}$ are apparently same suggesting the similar nature of both the forms. In the same way, Forms $\mathrm{III}_{\mathrm{H}}, \mathrm{IV}_{\mathrm{H}}$ and $\mathrm{V}_{\mathrm{H}}$ have similar molar enthalpy of solution which is comparable to Form $\mathrm{O}$ (Table 1). As expected, the molar enthalpy of solution of Form $\mathrm{VI}_{\mathrm{H}}$ is different from others suggesting it to be a new form.

In order to rule out the possibility of presence of small amount of high melting form as impurity in the low melting metastable polymorphic forms, a few additional experiments were performed. The enthalpy of solution of a mixture of the higher and lower melting forms in the ratio 1:1 was determined. The shape of the graph was found to be complex as compared to pure form. Figure 10 illustrates the enthalpy of solution of mixture of Form $\mathrm{V}_{\mathrm{L}}$ and $\mathrm{V}_{\mathrm{H}}$ (1:1). The splitting of the 


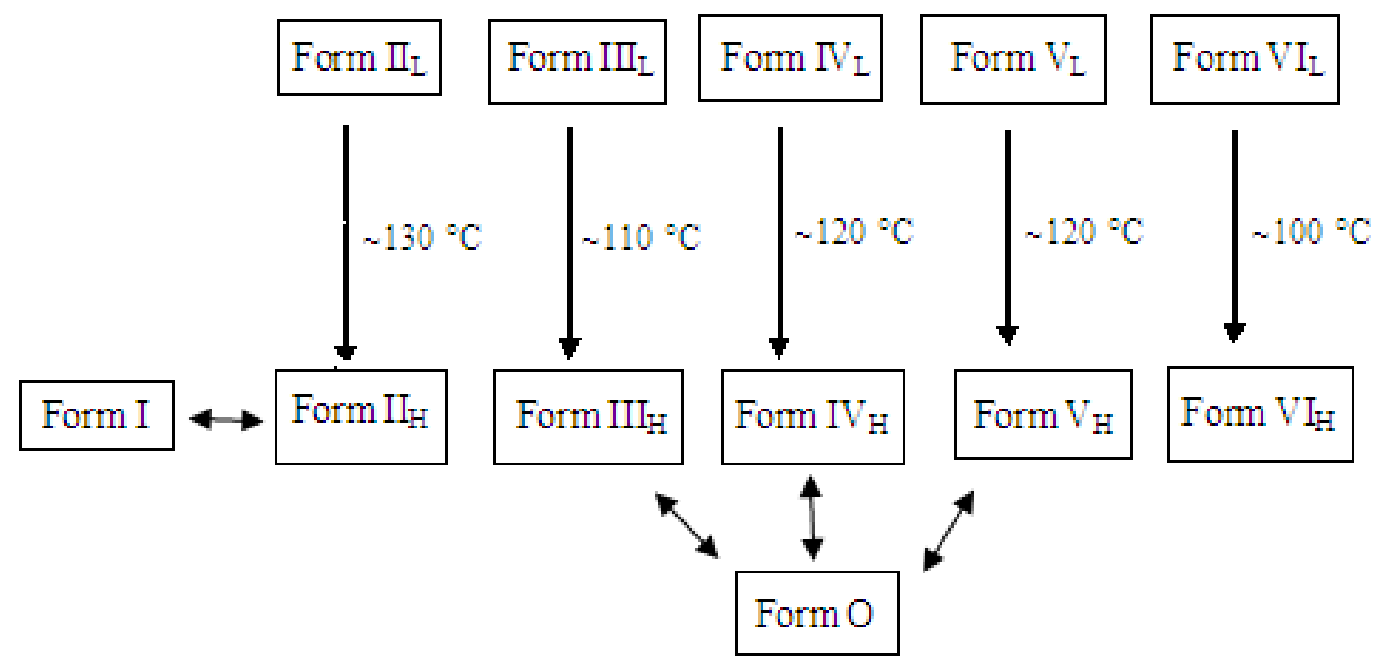

Scheme 1. Schematic diagram of relationship between various polymorphs of efavirenz.

endothermic signal is due to the presence of two polymorphs with different lattice energies and solubilities. The magnitude of enthalpy of solution of mixture was found to be $-9.34 \mathrm{~kJ} / \mathrm{mol}$. Similar curves are obtained for other mixtures. These experiments suggest the existence of pure polymorphic forms of efavirenz in the present study.

Variation in the solubility of all the forms is suggestive of existence of different forms and can not be attributed to difference in particle size as equilibrium solubility is not much affected by variations in the particle size except for the particles with very small size (less than $2 \mu$ ), however, in our study the particles are $10 \mu$ or more as shown by SEM graphs (27). Moreover, all the forms were sieved through mesh of $150 \mu$ before being subjected to solubility studies. Table 1 indicates that Form I is least soluble while Form $\mathrm{VI}_{\mathrm{L}}$ obtained from THF is most soluble with a $\sim 1.8$ times increase in solubility as compared to Form $\mathrm{O}$ (Table I). The solubility of low melting forms is higher than their corresponding forms, moreover, Form I is least soluble of all the forms and the form $\mathrm{VI}_{\mathrm{L}}$ is most soluble. As expected, the solubility of Form $\mathrm{III}_{\mathrm{H}}, \mathrm{IV}_{\mathrm{H}}, \mathrm{V}_{\mathrm{H}}$ is similar to Form $\mathrm{O}$ whereas the solubilities of Form $\mathrm{II}_{\mathrm{H}}$ and Form I are similar and quite different from that of Form $\mathrm{VI}_{\mathrm{H}}$. No change in the polymorphic identity determined by DSC and XRPD was observed in solid phase recovered from the solubility study of $24 \mathrm{~h}$ of all the polymorphic forms except for Form VI. This suggests that Form VI is converted to a new polymorphic form after subjecting to solubility studies for 1 week while all other forms were found to be quite stable in the acetate buffer $\mathrm{pH} 2.8$ even after 1 week. This further supports the presence of metastable polymorphs.

The table 1 shows the increase in solubility with temperature and this increase in solubility is due to very large positive values of entropy of solution varying from 66 to $107 \mathrm{~J} / \mathrm{mol} \mathrm{K}$.

The enthalpy of solution calculated from van't Hoff relationship from the temperature dependent solubility is not in agreement with calorimetricaly determined values. The discrepancies for the difference in the enthalpy of solution determined calorimetrically and those calculated from van't Hoff's equation are well documented in the literature $(28,29)$. However, in the present study the deviation is much more as compared to literature. This is attributed to the fact that solubility is dependent on free energy of solution which inturn is dependent upon entropy and enthalpy. In the present study, the change in solubility with temperature is dominated by large positive entropy of solution. The deviation from van't Hoff's equation becomes considerable when the contribution of the enthalpy change is small. 


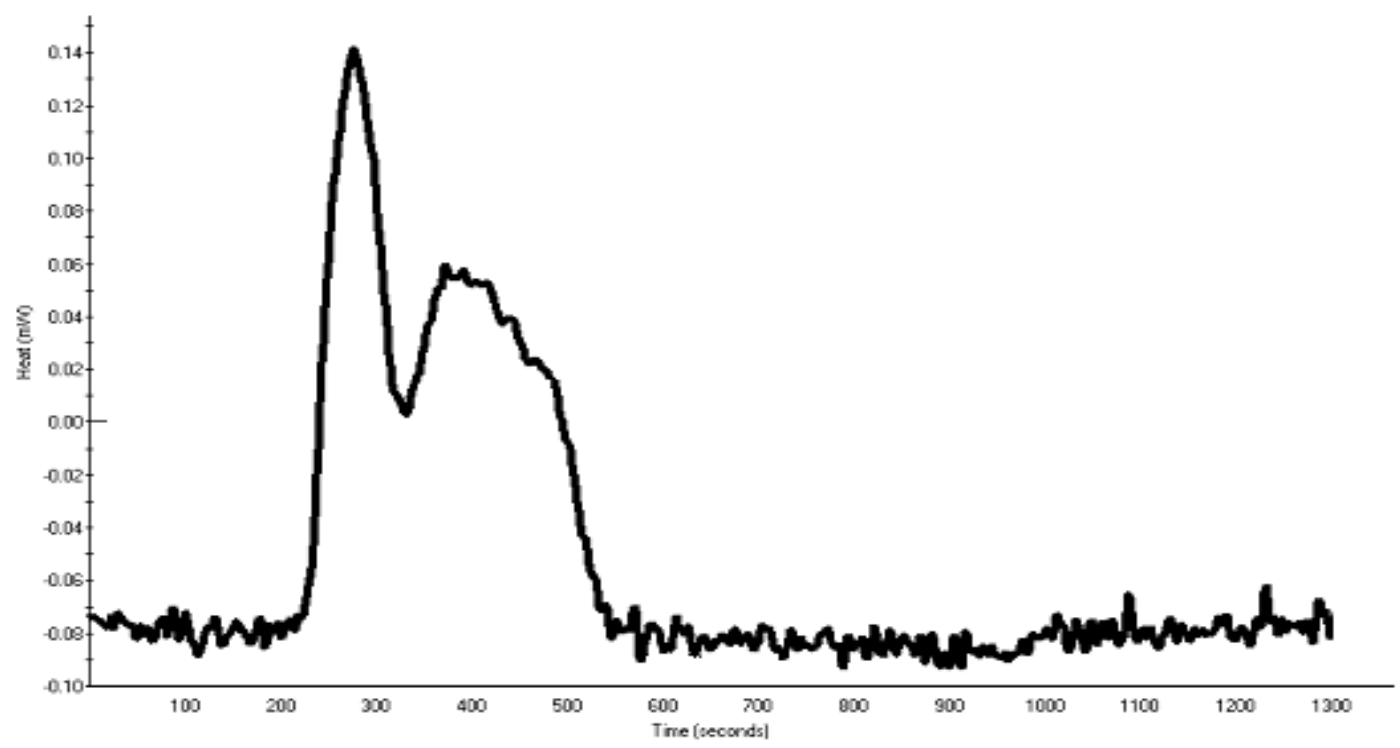

Figure 10. Representative graphs of enthalpy of solution a (1:1) mixture of the Form $\mathrm{V}_{\mathrm{L}}$ and $\mathrm{V}_{\mathrm{H}}$ forms in acetate buffer $\mathrm{pH} 2.8$.

\section{Estimation of thermodynamic stability relationship for polymorphic pairs}

The applicability of heat of transition rule which associates the exothermic transitions with the monotropic relationship and also the heat of fusion rule that relates high melting temperature accompanied by high enthalpy of fusion of a form with the monotropic relationship is confirmed in the previous section and Form $\mathrm{II}_{\mathrm{L}}, \mathrm{III}_{\mathrm{L}}, \mathrm{IV}_{\mathrm{L}}$ and $\mathrm{V}_{\mathrm{L}}$ were found to be monotropically related with their high melting forms. However, enantiotropy was found to exist between polymorphic pair $\mathrm{VI}_{\mathrm{L}} / \mathrm{VI}_{\mathrm{H}}$. The melting point data (30) and heat of solution data (31) can be used to determine the virtual temperature of transition in the polymorphic pairs. But in our study, the melting data method was not used to determine transition temperature because the enthalpy of fusion of lower melting is very small and it seems to overlap with exotherm which depicts the phase-phase transition (Table 1). This indicates that the melting process of metastable lower melting forms and the crystallization of the higher melting forms take place simultaneously. In order to give an insight into the stability relationship of monotropic polymorphic pairs and to find their virtual temperature of transition, enthalpy of solution method along with the solubility (32-39) are utilized in the present study. The enthalpy of transition $(\Delta \mathrm{H}(\mathrm{T}))$, free energy of transition $(\Delta \mathrm{G}(\mathrm{T}))$ and entropy of transition $(\Delta \mathrm{S}(\mathrm{T}))$ accompanying the transition of lower melting form to higher melting form are determined at $25^{\circ}, 37^{\circ}$ and $50^{\circ}$ using the following equations and are given in Table 3.

$$
\Delta H(T)=\Delta_{\text {sol }} H_{L}-\Delta_{\text {sol }} H_{H}
$$

where, $\Delta_{\text {sol }} \mathrm{H}_{\mathrm{L}}$ is the enthalpy of solution of lower melting form and $\Delta_{\text {sol }} \mathrm{H}_{\mathrm{H}}$ is the enthalpy of solution of higher melting form

$$
\Delta G(T)=-R T \ln s_{L} / s_{H}
$$

where, $\mathrm{s}_{\mathrm{L}}$ is the solubility of low melting polymorph and $\mathrm{s}_{\mathrm{H}}$ is the solubility of high melting polymorph The negative value of $\Delta G$ (Table 3 ) for transition of lower melting form $\mathrm{II}_{\mathrm{L}}-\mathrm{V}_{\mathrm{L}}$ to form $\mathrm{II}_{\mathrm{H}}-\mathrm{V}_{\mathrm{H}}$ respectively indicates that higher melting forms have lower Gibb's free energy. In the same way Form $\mathrm{O}$ and Form I has lower Gibbs free energy as compared to Form $\mathrm{VI}_{\mathrm{H}}$ whereas in the polymorphic pair O/I, the Form I has lower free energy. The entropy of transition between the two forms is calculated by the equation:

$$
\Delta S(T)=\{(\Delta H(T)-\Delta G(T)\} / T .
$$

It is found that the entropy of higher melting forms is lower than the lower melting forms (Table 3). However, the dominant factor in the free energy differences at all the temperatures and for all the polymorphic pairs is the difference between enthalpy between the two phases. At the transition temperature, $T_{t}$ 


$$
\Delta_{\text {trans }} \mathbf{G}=\mathbf{0}=\boldsymbol{\Delta}_{\text {trans }} \mathbf{H}-\mathrm{T}_{\mathrm{t}} \times \boldsymbol{\Delta}_{\text {trans }} \mathbf{S}, \text { hence, }
$$

$$
\mathbf{T}_{\mathbf{t}}=\Delta_{\text {trans }} \mathbf{H} / \Delta_{\text {trans }} \mathbf{S}
$$

The transition temperature for all the polymorphic pairs at the three temperatures is given in Table 3.

The work has been extended to take into account the effect of heat capacity on the transition temperature. The free energy difference between a polymorphic pair can be calculated at various temperatures by determining the heat capacity of low melting and high melting forms. The heat capacity of efavirenz and its various forms (low and high melting forms) has been determined at $25^{\circ}$ (Table 1). $\Delta \mathrm{C}_{\mathrm{p}}$ for the process: Form $\mathrm{L} \rightarrow$ Form $_{\mathrm{H}}$ (7) is given by 6 and is tabulated (Table 3 ).

$$
\Delta \mathbf{C}_{\mathrm{p}}=\mathbf{C}_{\mathrm{p}(\mathrm{H})}-\mathbf{C}_{\mathrm{p}(\mathrm{L})}
$$

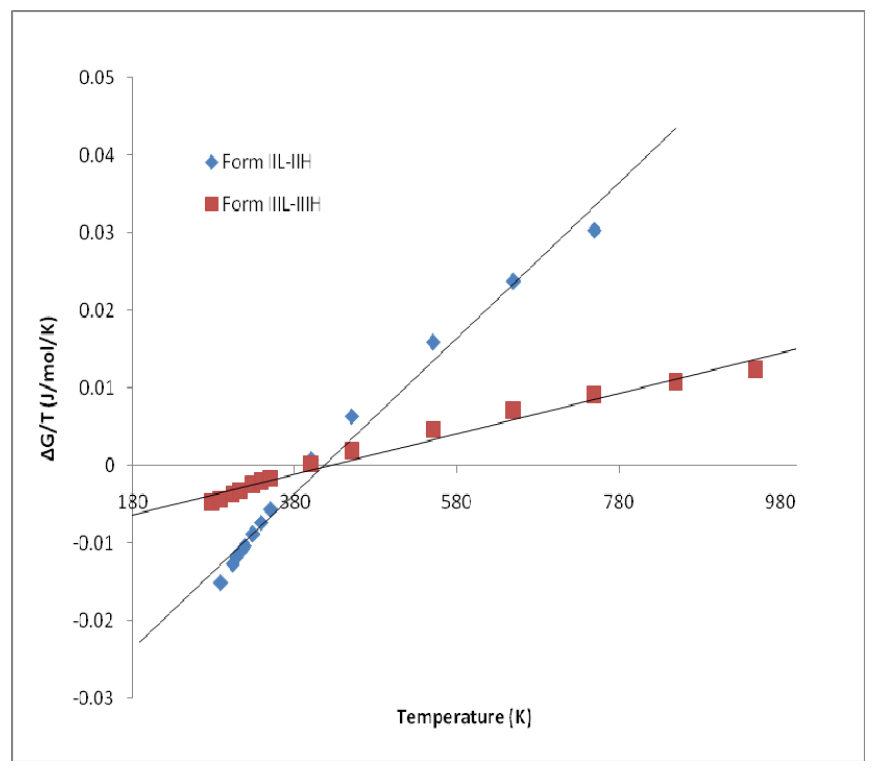

Figure 11. $\Delta \mathrm{G} / \mathrm{T}$ vs temperature plot for Form $\mathrm{II}_{\mathrm{L}} \longrightarrow$

$\mathrm{II}_{\mathrm{H}}$ and Form $\mathrm{III}_{\mathrm{L}} \longrightarrow \mathrm{III}_{\mathrm{H}}$ of efavirenz derived from $\Delta \mathrm{G}$ calculated by determining $\Delta \mathrm{Cp}$ experimently.

The experimentally determined $\Delta \mathrm{Cp}$ has been used to calculate $\Delta \mathrm{H}, \Delta \mathrm{S}$ and $\Delta \mathrm{G}$ for the process 7 using the equations

$$
\begin{aligned}
& \Delta H(T)=\Delta H\left(T_{0}\right)+\Delta C_{p}\left(T-T_{0}\right) . \\
& \left.\Delta S(T)=\Delta S\left(T_{0}\right)+\Delta C_{p} \ln T / T_{0}\right) .
\end{aligned}
$$

And
$\Delta G(T)=\Delta H(T)-T \Delta S(T)$

The plots between $\Delta \mathrm{G} / \mathrm{T}$ and $\mathrm{T}$ were found to be nearly linear (Figure 11) and the value of $T_{t}$ is determined at the point when $\Delta \mathrm{G} / \mathrm{T}$ intersects the $\mathrm{T}$ axis. The figure 11 shows transition temperature for Form $\mathrm{II}_{\mathrm{L}}-\mathrm{II}_{\mathrm{H}}$ and $\mathrm{III}_{\mathrm{L}}-\mathrm{III}_{\mathrm{H}}$ determined by plotting $\Delta \mathrm{G} / \mathrm{T}$ vs $\mathrm{T}$ graph. Similar, graphs were obtained for other forms. The values of virtual transition temperatures so determined are given in column 15 of Table 3. It can be seen from the Table II that the values of $T_{t}$ by taking into account $\Delta C p$ differs a little than calculated from equation 4 . The transition temperature of all the polymorphic pairs except Forms $\mathrm{VI}_{\mathrm{L}} / \mathrm{VI}_{\mathrm{H}}$ and $\mathrm{VI}_{\mathrm{H}} / \mathrm{I}$ is higher than the melting of both the forms determined from the equations 4 and 8 .

The existence of monotropy in these polymorphic pairs is very well indicated. In case of Forms $\mathrm{VI}_{\mathrm{L}} / \mathrm{VI}_{\mathrm{H}}$ as the transition temperature is between $0 \mathrm{~K}$ and the melting temperature of lower melting form, these forms exhibit enantiotropic relationship.

An important characteristic of these polymorphic systems is the high kinetic stability of these metastable forms except Form $\mathrm{VI}_{\mathrm{L}}$ at room temperature and can be suitable for use in pharmaceutical solid dosage form. The solvent mediated transformation has also indicated Form I to be the thermodynamically most stable form.

\section{CONCLUSION}

The existence of polymorphism in efavirenz is evident from the presence of two endothermic peaks separated by an exotherm as well as two endotherms in the DSC scans of various forms prepared. Thermodynamically, Form I was found to be most stable but has lowest solubility. The Forms $\mathrm{II}_{\mathrm{L}}, \mathrm{III}_{\mathrm{L}}, \mathrm{IV}_{\mathrm{L}}$ and $\mathrm{V}_{\mathrm{L}}$ were metastable and were found to be converted irreversibly to higher melting stable forms $\left(\mathrm{II}_{\mathrm{H}}, \mathrm{III}_{\mathrm{H}}, \mathrm{IV}_{\mathrm{H}}\right.$ and $\left.\mathrm{V}_{\mathrm{H}}\right)$ induced by heat. The virtual transition temperature of different polymorphic forms of efavirenz estimated by enthalpy of solution and solubility data is higher than the melting temperatures of higher melting forms in all the polymorphic pairs suggesting them to be monotropically related except polymorphic pair $\mathrm{VI}_{\mathrm{L}} / \mathrm{VI}_{\mathrm{H}}$ which shows enantiotropic behavior. The Form III $_{\mathrm{L}}$ seems to be most suitable as it exhibits the appropriate balance between the solubility and stability. The other metastable forms $\left(\mathrm{II}_{\mathrm{L}}, \mathrm{IV}_{\mathrm{L}}\right.$ and $\mathrm{V}_{\mathrm{L}}$ ) can be subjected to stability 
Table 3. Thermodynamic parameters for transition of low melting form to high melting form and the determination of transition temperatures

\begin{tabular}{|c|c|c|c|c|c|c|c|c|c|c|c|c|c|c|}
\hline & \multicolumn{3}{|c|}{$\Delta \mathrm{H}(\mathrm{kJ} / \mathrm{mol})^{\mathrm{a}}$} & \multicolumn{4}{|c|}{$\Delta \mathrm{G}(\mathrm{kJ} / \mathrm{mol})$} & \multicolumn{2}{|c|}{$\Delta \mathrm{S}(\mathrm{J} / \mathrm{mol})$} & \multicolumn{2}{|c|}{$\Delta \mathrm{Cp}^{\mathrm{b}}$} & \multicolumn{2}{|l|}{$\mathrm{T}_{\mathrm{t}}{ }^{\circ}$} & \multirow[t]{2}{*}{$\mathrm{T}_{\mathrm{t}},{ }^{\mathrm{oc}}$} \\
\hline & $25^{\circ}$ & $37^{\circ}$ & $50^{\circ}$ & $25^{\circ}$ & $37^{\circ}$ & $50^{\circ}$ & $25^{\circ}$ & $37^{\circ}$ & $50^{\circ}$ & $25^{\circ}$ & $25^{\circ}$ & $37^{\circ}$ & $50^{\circ}$ & \\
\hline $\begin{array}{l}\text { Form } \mathrm{O} \rightarrow \\
\text { Form I }\end{array}$ & -10.8 & -10.2 & -11.4 & -3.47 & -3.00 & -2.94 & -24.7 & -23.3 & -26.2 & -41.7 & 165.3 & 165.9 & 162.2 & 167 \\
\hline $\begin{array}{l}\text { Form II } \\
(\mathrm{L} \rightarrow \mathrm{H})\end{array}$ & -14.5 & -15.1 & -15.9 & -4.02 & -3.77 & -3.45 & -35.3 & -36.5 & -38.6 & -45.3 & 139.1 & 140.4 & 139.3 & 145 \\
\hline $\begin{array}{l}\text { Form III } \\
(\mathrm{L} \rightarrow \mathrm{H})\end{array}$ & -4.15 & -4.39 & -4.51 & -1.16 & -1.10 & -0.98 & -10.0 & -10.6 & -10.9 & -14.1 & 141.1 & 140.9 & 140.2 & 147 \\
\hline $\begin{array}{l}\text { Form IV } \\
(\mathrm{L} \rightarrow \mathrm{H})\end{array}$ & -2.54 & -2.63 & -2.74 & -0.79 & -0.74 & -0.69 & -5.89 & -6.11 & -6.4 & -9.29 & 158.4 & 158.4 & 158.8 & 167 \\
\hline $\begin{array}{l}\text { Form V } \\
(\mathrm{L} \rightarrow \mathrm{H})\end{array}$ & -3.18 & -3.26 & -3.37 & -1.26 & -1.21 & -1.15 & -6.44 & -6.62 & -6.85 & -8.94 & 220.7 & 220.3 & 218.3 & 227 \\
\hline $\begin{array}{l}\text { Form VI } \\
(\mathrm{L} \rightarrow \mathrm{H})\end{array}$ & -3.19 & -5.85 & -7.65 & -0.53 & -0.76 & -0.70 & -8.95 & -16.4 & -21.5 & -59.9 & 84.48 & 83.31 & 82.84 & 80 \\
\hline $\begin{array}{l}\text { Form VI } \rightarrow \\
\text { Form O }\end{array}$ & -2.95 & -2.94 & -3.32 & -0.84 & -0.74 & -0.73 & -7.05 & -7.07 & -7.98 & -15.8 & 145.3 & 143.1 & 142.5 & 145 \\
\hline $\begin{array}{l}\text { Form VI } \rightarrow \\
\text { Form I }\end{array}$ & -13.8 & -14.6 & -14.7 & -4.31 & -3.75 & -3.67 & -31.8 & -34.9 & -34.2 & -57.5 & 160.9 & 158.6 & 157.6 & 160 \\
\hline
\end{tabular}

L = Low melting form; $\mathrm{H}=$ High melting form; a, the differences between two measurements $<10 \%$; b, J/mol/K; c, by $\Delta \mathrm{G} / \mathrm{T}$ vs T Graph 
conditions to find out that if any of these metastable polymorphs is sufficiently stable and is having an acceptable shelf life it could be used for formulation. The stability studies are under consideration and are going on.

\section{ACKNOWLEDGEMENTS}

The financial support provided by Department of Science and Technology (DST), Government of India, is gratefully acknowledged.

\section{REFERENCES}

1. Brittain HG. Polymorphism and solvatomorphism 2007. J Pharm Sci, 2009; 98:1617-1642.

2. Hilfiker R, Blatter F, Raumer MV. Relevance of solid-state properties for pharmaceutical products. In Hilfiker R, editors. Polymorphism: in the pharmaceutical industry. Wiley-vch Verlag GmbH \& Co. KGaA, Weinheim, 2006; p 1-19.

3. Ricardo AEC, Teresa MRM, Antonio OLE, Joana CF, Silva MR, Matos BA, Joao C and Eusebio MES. A new insight into pyrazinamide polymorphic forms and their thermodynamic relationships. Crys. Growth \& design, 2010; 10: 274-282.

4. Grzesiak AL, Lang M, Kim K, Matzger AJ. Comparison of the four anhydrous polymorphs of carbamazepine and the crystal structure of Form I. J Pharm Sci, 2003; 92:2260-2271.

5. Zhang GGZ, Gu C, Zell MT, Burhardt RT, Munson EJ. Crystallization and transitions of sulfamerazine polymorphs. J Pharm Sci, 2002; 91:1089-1100.

6. Terada K, Kitano H, Yoshihashi Y, Yonemochi E. Quantitative correlation between initial dissolution rate and heat of solution of drug. Pharm Res, 2000; 17:920-924.

7. Beyer T, Day GM, Price SL. The Prediction, Morphology, and Mechanical Properties of the Polymorphs of Paracetamol. J Am Chem Soc, 2001; 123:5086-5094.

8. Aceves-Hernandez JM, Nicolas-Vazquez I, Aceves FJ, Hinojosa-Torres J. Indomethacin polymorphs: Experimental and conformational analysis. J Pharm Sci, 2009; 98:2448-2463.

9. Chauvet A, Masse J, Ribet JP, Bigg D, Autin JM, Maurel JL, Patoiseau JF, Jaud J. Characterization of polymorphs and solvates of 3-(Amino-1-(mtrifluoromethylphenyl)-6-methyl-1H-pyridazin-4one. J Pharm Sci, 1992; 81:836-841.

10. Okumura T, Otsuka M. A novel standard sample powder preparation method for Quantitative Analysis of Polymorphs. J Pharm Sci, 2005; 94:1013-1023.

11. Pudipeddi M, Serajuddin ATM. Trends in solubility of polymorphs. J Pharm Sci, 2005; 94: 929-937.
12. Radesca L, Maurin M, Rabel S, Moore J. Crystalline efavirenz, 1999; WO 99/64405.

13. Radesca L, Maurin M, Rabel S, Moore J. Crystalline efavirenz, 2004; US 6,673,372 B1.

14. Sharma R, Bhushan HK, Aryan RC, Singh N, Pandya B, Kumar Y. Polymorphic forms of efavirenz and processes for their preparation, 2006; WO 2006/040643 A2.

15. Khanduri HC, Panda AK, Kumar Y. Processes for the preparation of polymorphs of efavirenz, 2006; WO 2006/030299 A1.

16. Reddy BP, Rathnakar K, Reddy RR, Reddy DM, Reddy KSC. Novel polymorphs of efavirenz, 2006; US 2006/0235008.

17. Dova E. Polymorphic forms of efavirenz, 2008; WO 2008/108630 A1.

18. Ravikumar K, Sridhar B. Molecular and crystal structure of efavirenz, a potent and specific inhibitor ofHIV-1 reverse transcriptase, and its monohydrate. Mol Cryst Liq Crystal, 2009; 515:190-198.

19. Indian Pharmacopeia. $5^{\text {th }}$ ed., The Indian Pharmacopoeia Commission. Central Indian Pharmacopoeia Laboratory, Ghaziabad, India, 2007; p 242.

20. Haleblian JK. Characterization of habits and crystalline modification of solids and their pharmaceutical applications. J Pharm Sci. 1975; 64: 1269-1286.

21. Maurin RB, Rowe SM, Blom K, Pierce ME. Kinetics and mechanism of hydrolysis of efavirenz. Pharm Res. 2002; 19: 517-521.

22. Craig DQM, Reading M. Thermal analysis of pharmaceuticals. CRC Press, New York, 2007.

23. Kawakami K. Reversibilty of enantiotropically related polymorphic transformations from a practical viewpoint: Thermal analysis of kinetically reversible/irreversible polymorphic transformations. J Pharm Sci, 2007; 96:982-989.

24. Giron D. Thermal analysis and calorimetric methods in the characterization of polymorphs and solvates. Thermochim Acta, 1995; 248:1-59.

25. Behme RJ, Brooke D. Heat of fusion measurement of a low melting polymorph of carbamazepine that undergoes multiple phase changes during differential scanning calorimetry analysis. J Pharm Sci, 1991; 80:986-990.

26. Urakami K. Characterization of pharmaceutical polymorphs by isothermal calorimetry. Curr Pharm Biotech, 2005; 6: 193-203.

27. Hammond RB, Pencheva K, Roberts KJ, Auffret. Quantifying solubility enhancement due to particle size reduction and crystal modification: Case study of acetyl salicylic acid. J Pharm Sci, 2007; 96: 19671973.

28. Naghibi H, Tamura A, Sturtevant JM. Significant discripancies between van't Hoff and calorimetric enthalpies. Proc Natl Acad Sci USA, 1995; 92: 5597-5599. 
29. Liu Y and Sturtevant JM. Significant discripancies between van't Hoff and calorimetric enthalpies. II. Protein Science, 1995; 4: 2559-2561.

30. L. Yu. Inferring thermodynamic stability relationship of polymorphs by melting data. J Pharm Sci, 1995; 84: 966-974.

31. Gu C-H, Grant DJW. Estimating the relative stability of polymorphs and hydrates from heat of solution and solubility data. J Pharm Sci, 2001; 90:1277-1287.

32. Foppoli A, Sangalli ME, Maroni A, Gazzaniga A, Caira MR, Giordano F. Polymorphism of NCX4016, an NO-releasing derivative of acetylsalicylic acid. J Pharm Sci, 2004; 93:521-53.

33. Greman M, Vrecer F, Meden A. Some physicochemical properties of doxazosin mesylate polymorphic forms and its amorphous state. J Therm Ana and Cal, 2002; 68:373-387.

34. Chauvet A, Masse J, Ribet JP, Bigg D, Autin JM, Maurel JL, Patoiseau JF, Jaud J. Characterization of polymorphs and solvates of 3-Amino-1- $(m-$ trifluoromethylphenyl)-6-methyl-1H-pyridazin-4one. J Pharm Sci, 1992; 81:836-841.
35. Ghodbane S, McCauley JA. Study of the polymorphism of 3-(((3-(2-(7-chloro-2-quinolinyl)(E)-ethenyl)phenyl)((3-(dimethylamino-3-

oxoprpyl)thio)methyl)-thio)prpanoic acid (MK571) by DSC, TG, XRPD and solubility measurements. Int J Pharm, 1990; 59:281-286.

36. Ashizawa K. Polymorphism and crystal structure of 2R,4S,6-Fluoro-2-methyl-spiro[chroman-4,4'imidazoline]-2',5-dione (M79175). J Pharm Sci, 1999; 78:256-260.

37. Grzesiak AL, Lang M, Kim K, Matzger AJ. Comparison of the four anhydrous polymorphs of carbamazepine and the crystal structure of Form I. J Pharm Sci, 2003; 92:2260-2271.

38. Chang L-C, Caira MR, Guillory JK. Solid state characterization of dehydroepiandrosterone. J Pharm Sci, 1995; 84:1169-1179.

39. Griesser UJ, Burger A, Mereiter K. The polymorphic drug substances of the European Pharmacopeia. Part 9. Physicochemical properties and crystal structure of acetazolamide crystal forms. J Pharm Sci, 1997; 86:352-358. 